CHAPITRE 5

\title{
Perturbateurs hormonaux
}

JEAN-FRANÇOIS SAVOURET, DENIS BARD ET ANDRÉ PICOT 



\section{Résumé}

L'endocrinologie est passée en quelques décennies des hormones aux interactions entre hormones et récepteurs, puis aux mécanismes moléculaires du contrôle du métabolisme et de l'expression des gènes. Il fut rapidement observé que des molécules étrangères à la physiologie, les xénobiotiques, pouvaient $s^{\prime}$ immiscer dans ces équilibres pour les perturber.

Les premiers xénobiotiques identifiés comme perturbateurs hormonaux furent des toxines végétales ou des composés chimiques utilisés par les industries et diverses activités humaines et répandus dans l'environnement au cours de leur utilisation ou de leur élimination incontrôlée. De nombreux exemples de troubles du développement sexuel et de la reproduction causés par ces perturbateurs hormonaux ont été analysés sous l'angle de la toxicologie environnementale et de la pollution. Les effets œstrogéniques des insecticides et des antifongiques sont l'exemple le plus connu. Certains xénobiotiques, comme les dioxines, montrent une aptitude à l'activation de récepteurs "orphelins», aux ligands inconnus, capables de générer leurs propres régulations autant que de perturber celles de couples hormone/récepteur connus.

Un nouveau chapitre s'écrit aujourd'hui avec le double élargissement du concept de perturbation hormonale. D'une part, celle-ci se doit maintenant d'englober toute l'endocrinologie et non plus seulement la reproduction, comme en témoignent les exemples présentés du tabagisme et du diabète. D'autre part, de nouveaux xénobiotiques présents dans l'alimentation, naturellement (phytoœstrogènes) ou comme additifs autorisés, rejoignent les polluants industriels dans la liste des molécules à surveiller, de par leur utilisation en association, leur consommation parfois massive (soja) et leurs effets biologiques encore incomplètement documentés dans tous les domaines de la physiologie.

Cette liste en augmentation constante a conduit à la création du projet REACH (acronyme anglais pour enregistrement, évaluation et autorisation des produits chimiques), en réponse à l'insuffisance actuelle des connaissances. Ce projet européen permettra l'élimination progressive des produits chimiques les plus dangereux. Les producteurs devront transmettre à une agence centrale européenne un dossier d'enregistrement contenant des données de sécurité sur les substances produites, données proportionnelles aux volumes de production. Le dossier sera évalué par des experts, en particulier pour les substances produites en grande quantité ou qui comportent un risque. Les composés " extrêmement préoccupants 》 (cancérigènes, toxiques bio-accumulatifs dont les perturbateurs hormonaux) seront éliminés et remplacés par des produits plus sûrs, à moins que l'industrie ne puisse prouver que ces substances aient un intérêt "socioéconomique » supérieur aux risques et que ces risques sont contrôlés. REACH 
devrait aussi permettre d'optimiser l'application du principe de précaution pour les nouvelles molécules.

Notre équilibre intérieur est donc de plus en plus confronté aux xénobiotiques, que ce soit par la pollution ou les procédés de l'alimentation industrielle. Les possibilités de potentialisation croisée entre polluants et/ou entre polluants et additifs alimentaires autorisés sont pratiquement inconnues. La recherche épidémiologique doit documenter l'exposition générale du public aux xénobiotiques et identifier l'exposition ou la vulnérabilité particulières de certaines populations à risque. La recherche fondamentale doit élucider les mécanismes d'action des xénobiotiques et développer la production de marqueurs, de techniques de détection et de mesure ainsi que d'agents thérapeutiques. Enfin, les pathologies liées aux xénobiotiques industriels doivent être reconsidérées dans le contexte de maladies professionnelles. Tout cela suppose que la science comme la législation agissent au niveau européen et international.

\section{1 | La perturbation hormonale}

\subsection{Définition}

Selon la Commission européenne, un perturbateur hormonal, plus communément appelé perturbateur endocrinien (PE) est une substance étrangère à l'organisme, qui produit des effets pathologiques sur l'organisme ou sur sa descendance, à la suite d'une modification de la fonction hormonale (European Workshop on the Impact of Endocrine Disrupters on Human Health and Wildlife, Weybridge, UK; 1996, European Union Report EUR17459).

Selon l'Agence américaine de l'environnement (EPA), un perturbateur endocrinien est un agent exogène qui interfère avec la production, la libération, le transport, le métabolisme, la liaison, l'action ou l'élimination des ligands naturels responsables du maintien de l'homéostasie et de la régulation du développement de l'organisme (Kavlock et al., 1996).

Ces définitions sont centrées sur la notion de xénobiotiques ou composés étrangers à l'organisme. La définition américaine est restreinte et ne conçoit que la perturbation immédiate des systèmes hormonaux en omettant les effets passant par des voies spécifiques des xénobiotiques ainsi que les effets transgénérationnels.

L'hypothèse des PE est née du recoupement d'études cliniques humaines en toxicologie de la reproduction et de la thyroïde et d'études de l'environnement 
sur des anomalies de la reproduction de diverses espèces animales. Dans une étude pionnière, l'analyse de 61 publications de spermogrammes effectuées entre 1938 et 1991 a montré une diminution régulière du nombre de spermatozoïdes (de 113 à $66 \times 10^{6} / \mathrm{ml}$ ) et du volume de sperme, suggérant une réduction de la fertilité masculine (Carlsen et al., 1992). Ces auteurs associent le phénomène avec l'augmentation concomitante d'autres altérations des gonades mâles (cryptorchidie, hypospadias) et des cancers du testicule. Skakkebaek et al. ont proposé de regrouper ces symptômes dans le cadre d'un syndrome de dysgénésie testiculaire, qui résulterait d'une surexposition des cellules de Leydig et de Sertoli à une influence œstrogénique extérieure durant la vie fœtale et les premières années (Skakkebaek et al., 2001). L'insuffisance leydigienne entraînerait une sous-exposition aux androgènes, responsable des troubles de la morphogenèse, tandis que l'atteinte sertolienne conduirait aux cancers du testicule et à l'insuffisance spermatique.

Au fil du temps, se sont ajoutés des résultats mettant en cause des contaminants environnementaux (Longo, 1980), des œstrogènes de synthèse (diéthylstilbestrol, DES), responsable de cancers chez les filles de patientes traitées durant leur grossesse (Clark et Portier, 1979 ; Mattingly et Stafl, 1976); enfin d'autres xéno-œstrogènes naturels ou industriels (Waller et al., 1996). Finalement, on associa à ces effets xéno-œstrogènes des pathologies observées au voisinage d'accidents industriels impliquant des hydrocarbures polycycliques aromatiques $(\mathrm{HAP})$, des dioxines et/ou des polyhalogénobiphényles (PHB). Ces composés reconnaissent et activent le récepteur orphelin Ah (aryl hydrocarbon receptor, AhR) mais certains sont aussi génotoxiques ou antithyroïdiens. L'ensemble de ces observations définit la perturbation hormonale qui fait l'objet d'un débat sur sa relation avec la diminution de la fertilité masculine, divers troubles de la reproduction et l'accroissement de la fréquence de cancers dont les cancers du testicule.

Plus de 23 millions de molécules sont répertoriées en 2004, les produits industriels représentent 100000 composés et 800 à 1000 nouveaux composés sont introduits chaque année. Pour la plupart, les données d'évaluation du risque sanitaire sont insuffisantes ou inexistantes. Le risque potentiel est encore augmenté par l'existence d'additifs alimentaires pour lesquels il existe très peu de données (Munro et al., 1999).

Les " pesticides » regroupent les insecticides, herbicides et antifongiques tandis que le concept de composés organohalogénés polluants persistants (POP) regroupe une douzaine de molécules dont le danger environnemental est avéré : aldrine, chlordane, DDT, dieldrine, biphényles, dioxines et furanes halogénés, endrine, heptachlore, hexachlorobenzène, mirex et toxaphène. 


\subsection{Mécanismes de la perturbation hormonale}

II existe deux types d'hormones, peptidiques ou non peptidiques. Ces dernières sont des molécules de taille réduite (300 à 400 angströms), souvent lipophiles qui comprennent des stéroïdes (œstrogènes, progestérone, androgènes, glucocorticoïdes), des acides aminés modifiés (hormones, neuromédiateurs), des lipides (prostaglandines, rétinoïdes...) et d'autres molécules complexes (rifampicine).

Les hormones peptidiques et les neuromédiateurs agissent par l'entremise de récepteurs situés à la surface des cellules. II n'y a pratiquement pas de données décrivant des interactions directes entre xénobiotiques et récepteurs membranaires dans le cadre de la perturbation endocrine. Les hormones lipophiles diffusent à travers la cellule pour interagir avec des récepteurs intracellulaires avec une affinité globalement nanomolaire. Ces récepteurs sont des protéines cytoplasmiques et/ou nucléaires dotées d'un site de liaison saturable et de haute affinité pour un ligand ou des ligands spécifiques. Cette saturabilité permet une compétition entre ligands pour un même récepteur. Le clonage des récepteurs stéroïdiens a montré leur homogénéité structurale et généré le concept d'une superfamille qui regroupe une cinquantaine de récepteurs plus de nombreux récepteurs " orphelins » (Aranda et Pascual, 2001). Ces derniers n'ont pas de ligand physiologique identifié mais on leur connaît des ligands naturels de basse affinité ou des ligands synthétiques.

Les récepteurs nucléaires présentent un domaine central de liaison à l'ADN ainsi que deux domaine d'activation de la transcription aux extrémités $\mathrm{N}$ - ef C-terminales. Le domaine de liaison à l'ADN se caractérise par deux motifs en boucle stabilisée par un atome de zinc (doigt de zinc), qui interagissent avec les sillons de l'hélice d'ADN. Le premier motif reconnaît spécifiquement la séquence de l'élément de réponse à l'hormone (HRE). Le deuxième motif lie l'ADN de façon non spécifique et stabilise l'interaction. Le domaine de liaison du ligand se situe dans la région C-terminale.

La liaison de l'hormone modifie la structure du récepteur. Cette étape permet de différencier deux types de récepteurs, homo- ou hétérodimériques. Les récepteurs homodimériques (ligands stéroïdiens) sont complexés à des protéines chaperones en l'absence d'hormone et n'ont pas d'affinité pour l'ADN. La liaison de l'hormone provoque la dissociation des protéines chaperones et l'apparition de l'affinité pour l'ADN. Cet ensemble de modifications constitue l'activation (Milgrom et al., 1973). L'interaction des récepteurs activés avec un ou plusieurs HRE présents dans la séquence d'un gène cible conduit au remodelage de la chromatine et à la modulation de la transcription de ce gène. Les récepteurs hétérodimériques (hormones thyrö̈diennes, lipides, rétinoïdes. . .) sont associés 
au récepteur RXR (récepteur $X$ de l'acide 9-cis rétinoïque) agissant comme cofacteur constitutif. Le couple hétéromérique est associé à l'ADN, complexé à des corépresseurs protéiques et à des enzymes qui s'opposent à l'ouverture de la chromatine (histone-désacétylases). Le rôle de l'hormone est alors de dissocier les corépresseurs du complexe qui va recruter des coactivateurs et des histoneacétylases (revue dans Aranda et Pascual, 2001).

Les PE sont aussi de petites molécules lipophiles et leurs effets perturbateurs s'observent à chaque étape du mécanisme d'action des récepteurs. Ils peuvent se lier aux récepteurs, générant une compétition avec I'hormone naturelle. Ils peuvent activer ou inhiber le récepteur au niveau de la machinerie transcriptionnelle, ou induire sa dégradation par le protéasome, provoquant une dysfonction de la voie de signalisation concernée. Les récepteurs " orphelins » (PPAR, PXR, $\mathrm{SXR}, \mathrm{CAR} \beta$ et BXR; figure 5.1) sont aussi des cibles de xénobiotiques perturbateurs. PXR est un récepteur nucléaire hétérodimérique associé à $R X R$ et exprimé dans le foie, l'utérus, l'ovaire et le placenta. Sa concentration augmente dans ces organes (à l'exception du placenta) à la fin de la grossesse, ce qui suggère son implication dans la protection du système fœto-maternel et en fait une cible pour la toxicité périnatale des xénobiotiques (Masuyama et al., 2001).

Les cytochromes P-450 sont une superfamille de mono-oxygénases qui catalysent la phase I (hydroxylation) de la métabolisation des xénobiotiques mais aussi de composés endogènes (stéroïdes). Ils se subdivisent en familles (CYP1, 2,3 ...) selon les substrats, puis en sous-familles (CYP 1A, 1B) et enfin en isoenzymes (CYP 1A1, 1A2). La figure 5.1 résume les corrélations entre les cytochromes $\mathrm{P}-450$ responsables du métabolisme des xénobiotiques et les récepteurs hormonaux qui en induisent l'expression.

\section{2 | Les initiatives internationales}

En 1992, la Conférence de Rio de Janeiro sur l'Environnement et le développement a défini six programmes dont le Programme international pour la sécurité chimique (IPCS, www.who.int/ipcs/en) qui associe l'Organisation mondiale de la santé, l'Organisation internationale du travail et le programme des $\mathrm{Na}^{-}$ tions unies pour l'environnement. Le Forum international sur la sécurité chimique (IFCS) et le Programme Inter-Organisations pour la gestion sûre des produits chimiques $(I O M C)$ ont été chargés de définir les stratégies de mesure du risque à plusieurs niveaux : définition du risque, identification des produits à risque, adéquation des méthodes de mesure et de criblage, exposition aux taux faibles et effets de synergie par mélange. 


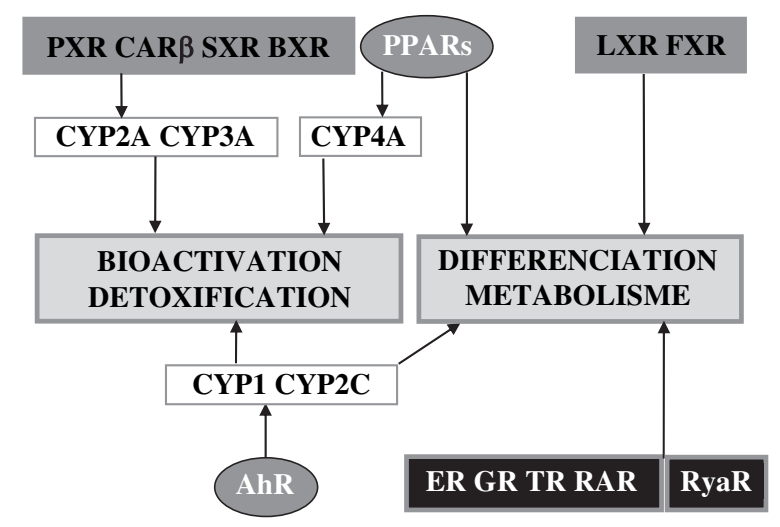

Récepteurs orphelins

Récepteurs à ligand identifié

Récepteurs

\section{Figure 5.1}

Récepteurs cibles des xénobiotiques.

Les récepteurs (PPARs et AhR) sont des récepteurs orphelins, PXR CARB SXR BXR et LXR FXR des récepteurs possédant de nombreux substrats sans préséance nette, ER GR TR RAR et RyaR des récepteurs à ligand identifié. Tous sont la cible de xénobiotiques.

$A h R$ : récepteur des HAP (et des dioxines). BXR : récepteur $X$ du benzoate. CAR $\beta$ : récepteur de l'androstane (activité constitutive). ER : récepteur des œstrogènes. FXR : récepteur $X$ du farnésyl. GR : récepteur des glucocorticoïdes. LXR : Liver X receptor : récepteur des 20/22-oxystérols. PPAR : récepteurs activés par les proliférateurs de peroxysomes $(\alpha \beta \gamma)$. RAR : récepteur des rétinoïdes $(\alpha \beta \gamma)$. PR : récepteur de la

progestérone. RyaR : canal calcique sensible à la ryanodine. SXR : steroid and xenobiotic receptor. TR : récepteur des hormones thyroidiennes $(\alpha \beta)$. CYP : cytochrome P-450.

Aux États-Unis, le National Institute of Health a créé le « National Toxicology Program's Center for the Evaluation of Risks to Human Reproduction ", chargé d'évaluer la perturbation hormonale. Un programme de détection des PE a été lancé dans le cadre du programme de qualité de la nourriture (Food Quality Protection Act, 1996). L'Agence américaine de l'environnement (EPA) a formé un comité des tests des PE (www.epa.gov/scipoly/oscpendo/edspoverview/edstac.htm) et a lancé en 2002 une campagne de tests pour détecter la perturbation hormonale au niveau de l'axe hypothalamogonadique et de la thyroïde sur le plan du métabolisme et des récepteurs hormonaux.

En Europe, la présence de polluants dans l'environnement fait l'objet $\mathrm{d}^{\prime}$ actions depuis le $4^{\mathrm{e}}$ Programme commun de recherche et développement (PCRD). Celui-ci comprend un groupe de quatre programmes (Credo, www.credocluster.info/intro.html). Les PCRD suivants ont prolongé ces actions (www.cordis.lu/food/home.html) en y adjoignant divers programmes 
de plus petite envergure, de type STREP. Un réseau d'excellence (Cascade, www.cascadenet.org) a été mis en place par le $6^{\mathrm{e}} \mathrm{PCRD}$. Le $7^{\mathrm{e}}$ programme annonce les mêmes intentions. Le Conseil européen de l'industrie chimique (Cefic) a lancé le "Long Range Research Initiative ", www.cefic-Iri.org). Ce programme a pour but de coordonner la recherche publique et privée en matière de santé et environnement et de créer une structure au niveau européen.

Au niveau français, le Comité de la prévention et de la précaution (CPP, ministère de l'Écologie et du Développement durable) publie des rapports réguliers sur le sujet (http://www.ecologie.gouv.fr/article.php3?id_article=1827), de même que l'Agence française de sécurité sanitaire des aliments (Afssa) qui a notamment publié en 2005 deux rapports sur les populations françaises exposées aux dioxines, PCB et furanes (http://www.afssa.fr/Ftp/Afssa/2550625507.pdf) ainsi que sur la balance risque/bénéfice des phytœstrogènes (http://www.afssa.fr/ftp/afssa/28468-28469.pdf). Le groupe Ecrin est une initiative intéressante qui relie l'industrie publique et privée, les acteurs de la recherche et les pouvoirs publics (www.ecrin.asso.fr).

\section{Sources et absorption des xénobiotiques}

\subsection{Eau}

L'eau est une source potentielle d'exposition aux PE. Ces molécules, même lipophiles, peuvent se retrouver dans l'eau par adsorption sur des particules. On trouve, à côté de perturbateurs d'origine industrielle, des produits pharmaceutiques tels qu'antibiotiques, anti-inflammatoires, $\beta$-bloquants et hormones (Bendz et al., 2005). Ces dernières comprennent des hormones de synthèse à but thérapeutique ou vétérinaire dont le devenir est mal connu. Les concentrations trouvées vont du $\mathrm{ng} / \mathrm{L}$ au $\mu \mathrm{g} / \mathrm{L}$, ce qui peut être significatif dans le cas de produits à forte activité. Une revue récente du Centre international de recherche sur l'eau et l'environnement (Suez Environnement) décrit l'état de la question (Bruchet et Janex-Habibi, 2004). Selon leur usage, ces composés rejoignent une station d'épuration où ils sont partiellement dégradés, ou sont introduits dans l'environnement par ruissellement. On peut les retrouver dans des eaux de surface susceptibles d'être utilisées comme ressources pour l'eau potable. Des observations réalisées sur la faune sauvage ont révélé des anomalies des coquilles d'œuf et des troubles de la reproduction des poissons d'estuaires ou des phoques se nourrissant de poissons contaminés (Sumpter, 1998).

La directive cadre sur l'eau intègre une liste de composés perturbateurs à éradiquer des rejets à l'horizon 2015 (Union européenne, 2000). Cette liste 
comprend des œstrogènes, des pesticides, des solvants organiques, des HAP, des biphényles halogénés, des détergents et leurs métabolites, des phthalates, le bisphénol $A$ et certains médicaments et cosmétiques. La dégradation des xénobiotiques par les stations d'épuration conventionnelles est partielle, mais peut être complétée par un traitement de nitrification/dénitrification ou ozonisation. L'oxydation à l'ozone couplée à un traitement d'affinage (adsorption sur charbon ou membranes) est capable d'éliminer la plupart des PE, tels que pesticides ou plastifiants. En revanche, les organohalogénés (PCB, dioxines) et les phthalates requièrent un traitement d'oxydation radicalaire. L'innocuité de cette technique $\mathrm{n}^{\prime}$ est pas certaine en termes des sous-produits générés. Le couplage ultraviolets/eau oxygénée est efficace sur les stéroïdes.

\subsection{Alimentation et sources diffuses}

L'existence de certains congénères naturels des dioxines (identifiés dans des carrières de kaolin) est l'objet d'un débat, mais la présence des dioxines dans I'environnement est essentiellement liée à leur nature de sous-produits de l'industrie du chlore et à leur production par les incinérateurs industriels. Les dioxines présentes dans les sédiments de la Baltique à partir de 1960 proviennent notamment des rejets des usines de traitement de pâte à papier. L'analyse d'herbiers européens anciens montre clairement deux pics en matière de dioxines : le premier coïncide avec l'apparition des produits chlorés, le second avec l'implantation des incinérateurs. La baisse actuelle d'utilisation de dérivés chlorés suite à leur interdiction, couplée à la fermeture et/ou la mise aux normes des incinérateurs se traduit par une baisse de la contamination environnementale.

Les HAP tels que le benzo(a)pyrène (BaP) sont présents dans la fumée de cigarette, les gaz d'échappement, les émanations des fours industriels, la viande cuite au barbecue et même le lait maternel. Ces composés sont potentiellement plus importants que la dioxine en termes d'exposition des populations, bien que leur affinité pour le récepteur AhR soit 5-10 fois inférieure à celle de la TCDD (voir $\S 4.5$.). La métabolisation de certains hydrocarbures après leur absorption conduit à des composés beaucoup plus toxiques que la molécule originelle, capables de former des adduits covalents avec les bases de l'ADN, conduisant à des mutations par erreur de lecture du nucléotide substitué par l'ADN polymérase. C'est le cas du BaP du tabac et de la 3-nitrobenzanthrone des gaz d'échappement de moteurs diesel (Arlt et al., 2004). Ce dernier composé illustre l'évolution rapide des idées dans le domaine, la pollution par les moteurs à combustion étant encore récemment abordée du seul point de vue des émissions particulaires.

La voie alimentaire est la voie prépondérante de contamination. La nature souvent hydrophobe des xénobiotiques fait que les graisses animales en sont la 
source principale. Le lait autrefois équivalent à la viande en termes de contamination par les dioxines a fait l'objet de mesures sanitaires strictes en Europe et le maintien en deçà de la limite de 1 à 5 pg/g est maintenant acquis .(Inserm, 2000).

L'influence des barrières physiologiques telles que placentaire et hématoméningée a fait l'objet de quelques études. Le cerveau capte moins de dioxines que les autres organes en dépit de sa concentration en lipides, suggérant que la barrière hématoméningée s'oppose à leur passage (Bachour et al., 1998). Les dioxines et les PCB traversent le placenta (Nau et Bass, 1981). Les xénobiotiques cumulatifs (dioxines, furanes et biphényles halogénés) sont stockés dans la graisse corporelle. Cette charge peut se mobiliser à l'occasion d'une perte de poids soudaine ou de l'allaitement (Lackmann et al., 2004; Pohl et Hibbs, 1996). La mobilisation vers le lait maternel inflige une charge corporelle conséquente à l'enfant allaité qui met environ sept ans pour l'éliminer (Kreuzer et al., 1997).

\section{Les familles chimiques de perturbateurs endocriniens}

\subsection{Pesticides xéno-œstrogènes}

On trouve dans cette catégorie des fongicides (alachlore, amitrole, atrazine, bénomyl, acide 2,4,5-trichlorophénoxyacétique (agent orange), tributylétain, vinclozoline) et des insecticides (DDT (1,1-bis (p-chlorophényl)-2, 2,2trichloroéthane), méthoxychlore, chlordécone, dieldrine, endosulfan, chlordane, toxaphène). Ils sont actifs par eux-mêmes ou par leurs métabolites (Sonnenschein et Soto, 1998).

Ces composés trouvés à des concentrations très faibles dans l'environnement peuvent être œstrogènes vrais ou anti-androgènes. Ils sont capables d'activer les deux types de récepteur aux œstrogènes, $\operatorname{ER} \alpha$ et $\operatorname{ER} \beta$, l'effet résultant étant dépendant du tissu et du gène (Degen et al., 2002). Le DDT et le méthoxychlore perturbent le transport intracellulaire du calcium. Ils inhibent la prolifération cellulaire, inhibent l'expression de plusieurs gènes spécifiques du trophoblaste et induisent son apoptose (Derfoul et al., 2003). L'endosulfan, l'alachlore et la chlordécone sont des ligands compétitifs du récepteur de la progestérone (Vonier et al., 1996). La plupart de ces molécules présentent aussi des effets variés sur d'autres hormones telles que le cortisol, la thyroxine, l'insuline et l'hormone lutéotrope (Rawlings et al., 1998). 
Les fongicides de base dicarboximide (vinclozoline), I'herbicide Linuron (analogue de l'anti-androgène flutamide), le métabolite $p^{\prime} p^{\prime} D D E$ du DDT, certains pyréthrénoïdes (fenvalérate, perméthrine) et certains organophosphorés (méthylparathion) sont des antagonistes des androgènes (Curtis, 2001). L'atrazine est anti-androgénique et œstrogénique. Les métabolites de la vinclozoline inhibent la production de testostérone par le testicule foetal conduisant à une démasculinisation (revue dans Gray et al., 2001). Le DDT, le méthoxychlore et le lindane diminuent la taille des gonades et la fertilité chez les rongeurs (revue dans Pocar et al., 2003). Les effets négatifs du lindane sur la spermatogenèse, très documentés pour les animaux, le sont beaucoup moins pour l'espèce humaine (Pages et al., 2002).

Certains pesticides (propiconazole, tributylétain) ne lient pas le récepteur des androgènes mais présentent des effets enzymatiques de type anti-aromatase ou anti- $5 \alpha$-réductase. Le tribultylétain est présent dans les peintures de bateau comme anti-mollusque et anti-algue. Il présente un effet de type " imposex», à savoir la superposition des deux types de tractus génital chez les mollusques et la féminisation de poissons mâles (Doering et al., 2002; Sumpter, 1998). Les effets sur l'homme ne sont pas documentés.

\subsection{Plastifiants et produits industriels divers}

Conçu dans les années 1930 en tant qu'œstrogène de synthèse, le bisphénol $A$, ou 2,2-bis-(4,4'-hydroxyphényl)-propane est aujourd'hui le monomère de base d'un certain nombre de matières plastiques et ciments dentaires. II est œstrogénique in vivo (Nagel et al., 1999), induit des aneuplö̈dies et forme des adduits covalents à l'ADN chez les rongeurs (Hunt et al., 2003). II existe une littérature abondante sur le bisphénol $A$ ainsi que sur des composés similaires ( $p$-nonylphénol, 4-tertioctylphénol) mais son analyse suggère que les effets toxiques et génotoxiques sont plus à prendre en considération que les effets œstrogéniques. Le p-nonylphénol est utilisé dans l'industrie (plastiques, détergents). Son utilisation fréquente et sa stabilité ont pour conséquence une contamination croissante des cours d'eau. Les effets œestrogéniques du p-nonylphénol et du 4-tertioctylphénol sont relatés dans un grand nombre de publications utilisant des modèles animaux ou des cultures in vitro (revue dans Sonnenschein et Soto, 1998). Leur faible concentration dans l'environnement et leur faible activité ont servi d'argument pour conclure à une absence de risque humain (Bolt et al., 2001 ; Degen et al., 2002), bien qu'une étude récente sur 37 femmes enceintes rapporte des taux sanguins comparables à ceux induisant des effets toxiques dans les modèles animaux (Schonfelder et al., 2002).

Le styrène est utilisé dans la chimie des plastiques. On considère aujourd'hui qu'il n'a aucun effet perturbateur et que les rapports initiaux de tels effets 
chez des populations exposées professionnellement étaient dus à des expositions multiples mal analysées et/ou des méthodologies inappropriées (Brown et al., 2000).

Les phosphates de triaryle sont utilisés comme ignifugeants, lubrifiants, et plastifiants. Ils activent de façon variable les récepteurs PXR et CAR $\beta$ de lignées cellulaires humaines en culture, modulent l'activité du récepteur des androgènes de rat et perturbent le cycle menstruel de ces rongeurs (Latendresse et al., 1995).

Les phthalates (prototype : le DEHP ou phthalate de di-2-éthylhexyle) sont utilisés dans la production de matières plastiques. Ces composés, considérés comme des anti-androgènes indirects agissant sur la stérö̈logenèse, ont été mis en cause dans la survenue de tumeurs (Klaunig et al., 2003) et d'anomalies du tractus génital chez le rat (Gray Jr. et al., 2000). Un panel d'experts du "National Toxicology Program's Center for the Evaluation of Risks to Human Reproduction 》 américain a publié une série de monographies sur les effets des phthalates (Kavlock et al., 2002). Malgré l'importance de la production industrielle en millions de tonnes et la présence massive de plastiques dans l'environnement humain, ce rapport considère que le risque de perturbation hormonale par les phthalates est minimal, voire nul. Une expertise récente a réitéré ce jugement (McKee et al., 2004) mais ce dernier travail a été sévèrement critiqué pour sa tendance à renforcer l'image inoffensive des phthalates par une sélection orientée des résultats présentés, les phthalates étant un colossal enjeu industriel (Koch et al., 2004). De récents résultats sur une cohorte humaine remettent à l'ordre du jour le risque présenté par les phthalates au niveau des dystrophies génitales (Swan et al., 2005). Une revue récente soutient la nécessité de reconsidérer le problème en l'élargissant sur le plan moléculaire car ces composés sont aussi des ligands des trois récepteurs activés par les proliférateurs de peroxisomes PPAR $\alpha, \beta, \gamma$. Ils sont susceptibles à ce titre d'influer sur les grandes fonctions métaboliques et le diabète (Corton et Lapinskas, 2005).

\subsection{Xénobiotiques végétaux et phyto-œstrogènes}

Cette famille comprend des mycotoxines, des toxines d'organismes marins, des antibiotiques et des phyło-œstrogènes tels que coumestanes, zéaralénone et polyphénols. Ceux-ci regroupent les isoflavones (génistéine, daidzéine), flavonoïdes (quercétine) et hydroxystilbènes (resvératrol). Des cyanobactéries marines produisent des diphényléthers bromés analogues des PHB (Moore, 1999).

Les phyto-œstrogènes alimentaires sont présents essentiellement dans les légumineuses (génistéine et daidzéine du soja) (Polkowski et Mazurek, 2000). Ils représentent $1 \mathrm{mg} / \mathrm{kg}$ de poids par jour chez l'adulte et $5-8 \mathrm{mg} / \mathrm{kg}$ chez les nourrissons suite à la consommation de formules lactées au soja (Setchell et al., 
1997). Les phyto-œstrogènes sont agonistes des $E R \alpha$ et $\beta$ in vitro et in vivo chez l'animal et chez l'homme (revue dans Benassayag et al., 2002). La génistéine apparaît comme le chef de file des phyto-œstrogènes, de par son affinité significative pour $E R \alpha(K d: 100 \mathrm{nM})$ et sa proportion élevée (65\%) dans les phyto-œstrogènes de soja. Cette affinité peut être préoccupante lorsqu'on sait que les taux plasmatiques de génistéine chez les enfants nourris au lait de soja sont 13 à 22000 fois supérieurs à leur taux d'œstradiol circulant (Setchell et al., 1998).

L'intérêt pour les phyło-œstrogènes fut initialement basé sur des propriétés observées dans différents modèles in vitro et in vivo (anticancéreux, antioxydants, hypolipémiants et protecteurs vis-à-vis de l'ostéoporose). La surmédiatisation de ces effets potentiellement bénéfiques a conduit à une augmentation considérable de leur consommation sous la forme de suppléments diététiques auto-administrés sans contrôle. On assiste aujourd'hui à une remise en question de ces effets. La méthodologie des expérimentations initiales est critiquée (Erdman Jr. et al., 2004). Beaucoup apparaissent comme peu reproductibles lors d'essais cliniques ou ne peuvent être attribués à un mécanisme précis (revue dans Sirtori et al., 2005). Les données humaines sont trop limitées et le risque de déclenchement ou d'aggravation de cancers œstrogénodépendants est insuffisamment exploré (Mishra et al., 2003). Néanmoins, une étude sur près de 2500 personnes montre une corrélation inverse entre la consommation normale de flavonoïdes alimentaires et le risque de cancer du sein en Grèce (Peterson et al., 2003).

La situation est rendue complexe par la multiplicité des mécanismes d'action des phyto-œstrogènes : ils sont agonistes des $\mathrm{ER} \alpha$ et $\beta$ (revue dans Benassayag et al., 2002), antagonistes compétitifs du récepteur AhR (revue dans (Zhang et al., 2003)) et inhibiteurs des tyrosine kinases (Dixon et Ferreira, 2002). $\grave{A}$ haute dose, les phyło-œstrogènes présentent des effets indésirables (prooxydants, mutagènes) (revue dans Skibola et Smith, 2000). La quercétine aggrave les tumeurs du rein induites par l'œstradiol chez le hamster et la génistéine perturbe le cycle cellulaire (de Lemos, 2001). La génistéine présente des effets chimioprotecteurs mais ses métabolites oxydés sont génotoxiques (Lutz et al., 2005). Des études in vivo sur les rongeurs mettent en cause les phyto-œstrogènes dans des phénomènes de toxicité épigénétique (§ 5.7.).

\subsection{Polyhalogénobiphényles}

Les polyhalogénobiphényles (PHB) se divisent en polychlorés et polybromés dont les dérivés bromés du bisphénol $A$. Tous sont des toxiques environnementaux persistants et bioaccumulables. Les dérivés polybromés ont été créés pour 
remplacer les $\mathrm{PCB}$ toxiques dans les procédés d'ignifugeage mais leurs propriétés perturbatrices se sont avérées comparables. Les PCB sont des huiles synthétiques employées dans l'industrie à de multiples titres (liquides caloporteurs, ignifugeants, isolants, lubrifiants, peintures, encres et plastiques). On estime à 100000 tonnes la quantité de PCB dans la biosphère, bien qu'ils soient aujourd'hui interdits de fabrication et d'utilisation, au moins dans les pays occidentaux. Les différentes halogénations donnent lieu à 209 congénères de structure coplanaire ou non coplanaire. Les PCB coplanaires lient le récepteur AhR et seront traités avec les autres ligands AhR (§ 4.5.). Les PCB non coplanaires ne lient pas AhR. Tous interfèrent avec la signalisation et le métabolisme des hormones thyroïdiennes. La chaleur dégagée par les incendies convertit les PCB en polychlorodibenzofuranes (PCDF) par époxydation intramoléculaire. Les PCDF ont des propriétés analogues à celles des dioxines.

Les PCB pénètrent facilement dans l'organisme. On trouve des concentrations de 4,7 à $27 \mu \mathrm{g} / \mathrm{L}$ dans le plasma de populations exposées (Invits) (Ayotte et al., 1997). Ces composés présentent un impact systémique sur la reproduction des animaux. Ils perturbent l'activité aromatase hypothalamique responsable de la sexuation du cerveau chez les rongeurs et induisent une diminution du nombre de cellules germinales, une embryotoxicité et une diminution de la taille des portées. On observe une diminution de la fécondité chez les bovins mais les études les plus récentes contredisent les relations initiales d'une toxicité des PCB sur la reproduction humaine (Sugiura-Ogasawara et al., 2003). En revanche, les études faites dans le cadre du 4 e PCRD ont conduit à un consensus sur leur toxicité neurologique (http://europa.eu.int/comm/research/endocrine/projects_completed_en.html).

\subsection{Les dioxines et autres ligands du récepteur AhR}

En 1976, I'explosion de l'usine de pesticides ICMESA de Seveso (Italie) libéra dans l'atmosphère de grandes quantités de dioxines dont la dioxine prototype, dite « de Seveso » : 2, 3, 7,8-tétrachlorodibenzo-p-dioxine, TCDD. Ces dioxines furent générées par la pyrolyse de trichlorophénols. Deux cohortes ont été définies pour assurer la surveillance épidémiologique de cette population qui fut sévèrement exposée. Le groupe de Bertazzi mène des campagnes biennales depuis les annés 1980 (Bertazzi et al., 1989). Ils ont observé une modification du sex ratio en faveur des filles ainsi que des variations progressives de certains risques de pathologies (cancers, diabète) (Pesatori et al., 2003). La cohorte du "Seveso Women's Health Study » comporte 981 femmes résidantes des zones d'exposition les plus contaminées de Seveso et âgées de moins de quarante ans au moment de l'accident. Cette équipe a détecté un lien entre exposition aux dioxines et risque de cancer du sein mais pas d'association avec le risque d'avortement spontané, de faible poids de naissance ou de prématurité 
(Eskenazi et al., 2003). Pour une analyse exhaustive sur la TCDD, on se reportera à l'expertise collective Inserm : «Dioxines dans l'environnement 》 (Inserm, 2000).

Les HAP, les PCB coplanaires et les polychlorodibenzodioxines et furanes (PCDD dont TCDD et PCDF) sont les ligands principaux du AhR. AhR reconnaît plus de 250 ligands dont 75 dioxines, le carbaryl, un carbamate insecticide et l'anthelminthique thiabendazole, mais le ligand naturel de ce récepteur reste inconnu malgré quelques molécules candidates (revue dans Denison et Nagy, 2003). Les ligands AhR ont une affinité pour AhR qui varie entre 2-8 nM (dioxines) et 10-20 nM (HAP) selon les espèces (Collins et Marletta, 1984 ; Perdew et Hollenback, 1990). Un certain nombre de phyto-œstrogènes sont des antagonistes du AhR tels la génistéine ou le resvératrol (Kd 100 nM). Un modulateur physiologique antagoniste a été identifié, le 7-oxocholestérol (Savouret et al., 2001). La toxicité des dioxines diffère selon les espèces et selon les organes.

AhR est cytoplasmique en l'absence de ligand et n'a aucune analogie avec les récepteurs stéroïdiens. II se caractérise par un domaine $\mathrm{N}$-terminal complexe bHLH-PAS, responsable de la liaison à l'ADN, de l'hétérodimérisation et de la liaison du ligand et des chaperones. Ce domaine définit une famille de transactivateurs qui comprend, outre AhR, son partenaire d'hétérodimérisation nucléaire ARNT (aryl-hydrocarbon receptor nuclear translocator), le facteur de réponse à l'hypoxie HIF $1 \alpha$ et le coactivateur des récepteurs stéroïdiens SRC-1 (Rowlands et Gustafsson, 1997). La partie C-terminale du récepteur AhR contient des régions transactivatrices et une fonction de répression de la transcription (Whitelaw et al., 1994). AhR présente une rare aptitude aux interactions avec d'autres protéines telles que chaperones (HSP90), le répresseur spécifique $A h R R$, le récepteur des œstrogènes, le corépresseur SMRT, des facteurs et cofacteurs de transcription et des tyrosine kinases (revue dans Carlson et Perdew, 2002). Toutes ces interactions sont susceptibles de générer des effets de perturbation hormonale puisqu'elles concernent des voies de signalisation hormonale.

Après interaction avec son ligand, AhR se libère des chaperones et le complexe migre du cytoplasme vers le noyau. II s'associe avec ARNT pour réguler l'expression de certains gènes en se liant à l'ADN au niveau de séquences définies, les "dioxin (ou xenobiotic) responsive elements 》 (DRE, XRE). Ces éléments sont présents dans la séquence des gènes cibles comme les cytochromes P-450 1A et 1B (CYP1A, 1B, mono-oxygénases de phase I) ou les enzymes de la phase II de la détoxification (gluthathione S-transférases, UDP glucuronyl transférase...). Les DRE existent aussi sous forme de sites inhibiteurs (iDRE) qui imposent une répression dioxine-dépendante au gène qui les contient (Safe et al., 1998). Les iDRE sont des DRE dont les adénines extrêmes sont remplacées par des cytidines (tableau 5.1). On trouve ces iDRE dans des gènes de la 
sphère hormonale (c-fos (Duan et al., 1999) ; pS2 (Gillesby et al., 1997)). Un XRE variant a été identifié dans le gène de la Paraoxonase 1 qui métabolise les pesticides organophosphorés. Ce site ne permet pas la transactivation par la TCDD mais induit une réponse agoniste par les HAP et les polyphénols (tableau 5.1) (Govedard et al., 2004). Lai et al., ont publié une première série de gènes contenant des DRE et pouvant donc être régulés par les ligands AhR (Lai et al., 1996). Une série plus exhaustive a été définie récemment in silico. Les gènes liés à l'inflammation y sont fortement représentés (Inserm 2000).

\subsection{Métaux et éléments mixtes}

L'arsenic, le cadmium, le plomb, le mercure, l'antimoine, le lithium, le baryum et le chrome présentent des effets œestrogéniques in vitro (Choe et al., 2003). Plusieurs études portant sur des employés d'usines utilisant le plomb rapportent des anomalies des taux d'hormone circulantes (prolactine, testostérone, $\mathrm{LH}$, follitropine ou FSH, thyréostimuline ou TSH) (revue dans Baccarelli et al., 2000).

Le cadmium est présent dans les déchets industriels et la fumée de tabac. II présente des effets contradictoires sur la synthèse de la progestérone en fonction des doses et du tissu étudié (Henson et Chedrese, 2004). Une exposition aiguë ( 3 à $5 \mathrm{mg} / \mathrm{kg}$ ) provoque une forte baisse des taux circulants de progestérone et d'œstradiol (Piasek et al., 1996). Le cadmium se lie au récepteur des œstrogènes et l'active in vivo et in vitro. Il augmente le développement de l'utérus et de la glande mammaire chez l'animal ovariectomisé, avec induction du récepteur de la progestérone (Johnson et al., 2003). Le cadmium induit aussi l'expression de pS2 dans des lignées de cancer du sein (Garcia-Morales et al., 1994). Cependant, le cadmium apparaît comme un facteur de risque de l'ostéoporose par sa compétition avec le calcium (revue dans Hu, 2000). L'arsenic est utilisé comme insecticide. Il inhibe réversiblement l'expression de ER $\alpha$ et son activité transcriptionnelle sur des gènes-cibles tels que pS2 (Garcia-Morales et al., 1994). L'arsenic interagit avec le récepteur des glucocorticoïdes à doses subtoxiques $(0,3-3,3 \mu \mathrm{M})$ et diminue son activité transactivatrice (Kaltreider et al., 2001).

\section{5 | Cibles et mécanismes d'action}

\subsection{Synthèse et transport des hormones}

Divers pesticides (aldicarbe, méthomyl, métribuzine) augmentent la thyroxine (T4) circulante et induisent une hyperthyroïdie chez le rat (Porter et al., 1993). 


\begin{tabular}{|l|c|c|c|c|c|c|c|c|c|c|}
\hline DRE & T & N & G & C & G & T & G & A/G & G/C & A \\
iDRE & C & N & G & C & G & T & G & A/G & G/C & C \\
Pon1-XRE & C & G & G & C & G & G & G & G & C & C \\
Bax-XRE & G & G & G & C & G & T & G & G & T & G \\
\hline
\end{tabular}

DRE iDRE Pon1-XRE BaX-XRE

\begin{tabular}{|c|c|c|c|c|}
\hline $\begin{array}{l}\text { TCDD : (2,3,7,8-tétrachlorodi- } \\
\text { benzo(p)dioxine) } \\
\text { PCDD (polychlorodibenzodioxines) } \\
\text { PCDF (polychlorodibenzofuranes) }\end{array}$ & $\begin{array}{l}+ \\
+ \\
+\end{array}$ & $\begin{array}{l}- \\
- \\
-\end{array}$ & $\begin{array}{l}- \\
- \\
-\end{array}$ & - \\
\hline $\begin{array}{l}\text { Benzo(a)pyrène } \\
\text { dibenz(a, h)anthracène } \\
\text { diméthyl 7, } 12 \text { benzanthracene } \\
\text { 3-méthyl-cholanthrène } \\
\text { indolo(3, 2-b)carbazole } \\
\text { 3,2-diindolylméthane }\end{array}$ & $\begin{array}{l}+ \\
+ \\
+ \\
+ \\
+ \\
+\end{array}$ & - & + & + \\
\hline
\end{tabular}
PCB (polychlorobiphényles)
mono-ortho
di-ortho
co-planaire

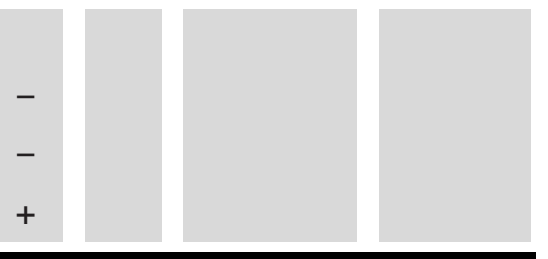

Quercétine

7, 8-alpha-naphtoflavone

7, 8-bêta-naphtoflavone

Resveratrol

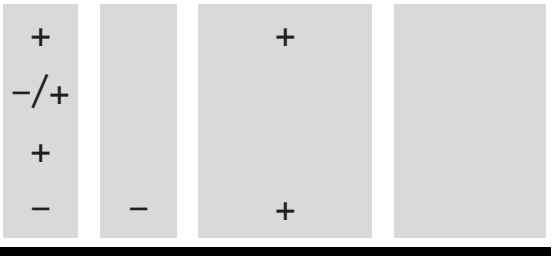

\section{Tableau 5.1}

Sites AND et ligands du récepteur AhR.

Les nucléotides en rouge divergent du DRE (dioxine responsive element) canonique. Le site Pon-1 (Gouedard et al., 2004) et le site Bax (Matikainen et al., 2001) sont qualifiés de XRE (xenobiotic responsive element) car leur spécificité exclut la dioxine. Les signes + signifient transactivation, les signes -, transrépression, l'absence de signe indique l'absence de données. L' $\alpha$-naphthoflavone est antagoniste jusqu'à $10^{-6} \mathrm{M}$ et agoniste au-delà de $10^{-5} \mathrm{M}$. 
Une étude de l'EPA montre que sur 240 pesticides testés, 24 (alachlor, amitrole, fipronil, mancozeb, pyréthrines, toxaphène, etc.) induisent l'apparition de cancers folliculaires de la thyroïde chez les rongeurs (Hurley, 1998). Seul l'acetochlor apparaît authentiquement mutagène. Les autres composés interfèrent avec la synthèse et/ou le catabolisme des hormones thyroïdiennes (T4; triiodothyronine, T3) et perturbent l'homéostasie de la glande (hypertrophie cellulaire, hyperplasie). La seule étude disponible chez les humains porte sur le mancozeb et ne retrouve pas les résultats obtenus chez les rongeurs (Nordby et al., 2005).

Certains fungicides (propiconazole, triadimefon, myclobutanil) augmentent le taux de cancers de la thyroïde chez la souris par un mécanisme inconnu.

Les métabolites hydroxylés des PCB sont inhibiteurs de la T2 sulfotransférase. La sulfatation des hormones thyrö̈diennes régule le niveau d'hormone libre chez le fœetus, ce qui pourrait expliquer l'impact des PHB sur le développement thyroïdien du fœtus (Schuur et al., 1998). Les PCB influencent le transport des hormones thyroïdiennes en liant la protéine de transport des rongeurs (transthyrétrine) mais pas le transporteur humain (Lans et al., 1994). Ils inhibent l'œstradiol-sulfotransférase et induisent une disponibilité accrue de l'œstradiol dans les tissus, conduisant à des effets œstrogéniques. Les PHB perturbent la synthèse des hormones hypophysaires ce qui retentit sur la reproduction des rongeurs et des animaux d'élevage (revue Gray et al., 2001 et le rapport du 4e PCRD, http://europa.eu.int/comm/research/endocrine/projects_completed_en.html). Ils perturbent la stérö̈dogenèse au niveau des androgènes (Cooke et al., 1998) et du cortisol (DiBartolomeis et al., 1987). Ils inhibent la transcription du cytochrome P450scc, ce qui diminue la stéroïdogenèse chez le rat (Moore et al., 1991).

Un certain nombre de pesticides (propiconazole, kétoconazole, tributylétain) et d'organochlorés perturbent la fonction androgénique par des effets enzymatiques de type anti-aromatase ou anti- $5 \alpha$-réductase.

Des travaux in vitro sur les cellules de la granulosa humaine en culture ont rapporté des effets de la TCDD sur la stéroïdogenèse (Pieklo et al., 2000), les voies de régulations des protéine-kinases (Enan et al., 1998), la prolifération cellulaire et le transport du glucose (Enan et al., 1992). Tous ces paramètres sont inhibés par la TCDD qui se présente comme un inhibiteur pléiotropique de la prolifération de ces cellules. Un effet proapoptotique a été également rapporté (Heimler et al., 1998). L'acide perfluorodécanö̈que, un surfactant présent dans les lubrifiants, perturbe la stéroïdogenèse au niveau du cyłochrome P450scc en inhibant le récepteur mitochondrial des benzodiazépines indispensable au transport du cholestérol (Papadopoulos et al., 1997). 
La situation dans les populations humaines est beaucoup moins claire. La littérature rapporte des effets négatifs des dioxines et des PCB sur l'ensemble de I'axe hypothalamogonadique, la stérö̈dogenèse leydigienne et la morphologie cellulaire (Schultz et al., 2003). Ces études décrivent des effets sur l'induction du CYP 1Al, la spermatogenèse et/ou les taux d'hormones circulantes sans proposer de mécanisme.

\subsection{Liaison directe aux récepteurs nucléaires}

Les xéno-œstrogènes lient et activent les récepteurs aux œstrogènes $(E R \alpha, \beta)$ en se fixant sur le site de liaison de l'hormone naturelle, ce qui conduit aussi à des effets de compétition. Les fongicides de base dicarboximide, le pp'DDE, des pyréthrénoïdes et des organophosphorés sont des antagonistes du récepteur des androgènes et le Linuron est un analogue structural de l'anti-androgène flutamide (Curtis, 2001). Les PCB présentent une forte analogie structurale avec les hormones thyroïdiennes. Ils lient les récepteurs thyroïdiens (McKinney et al., 1987) et inhibent leur interaction avec le coactivateur SRC1 (Iwasaki et al., 2002). Les hydroxy-PCB les plus aptes à imiter les hormones thyroïdiennes ont des $\mathrm{K}_{\mathrm{i}}$ voisins de 20-50 $\mu \mathrm{M}$ pour le récepteur $\mathrm{T} 3 \alpha$, contre $10 \mathrm{nM}$ pour l'hormone naturelle. Les dérivés méthane-sulfonyles des $P C B$, produits par la voie mercapturique, sont aussi des antagonistes compétitifs du récepteur des glucocorticoïdes (Johansson et al., 1998) mais les implications en pathologie humaine ne sont pas connues. L'endosulfan, I'alachlore et la chlordécone lient le récepteur de la progestérone, activité mise en cause dans leurs effets (Vonier et al., 1996). Les phthalates lient les récepteurs PPAR (Corton et Lapinskas, 2005 ; Maloney et Waxman, 1999), d'autres sont des antagonistes du récepteur des androgènes de rat (Barlow et al., 2003). Les phosphates de triaryle lient PXR et CAR $\beta$ (Honkakoski et al., 2004).

\subsection{Interférences entre AhR et récepteurs nucléaires}

Les ligands AhR sont anti-œstrogènes (revue dans Safe et Wormke, 2003). On distingue des effets transcriptionnels directs dus à des sites iDRE présents dans des gènes œstrogéno-dépendants et des effets d'interférence entre AhR et le récepteur $E R \alpha$ (Safe et al., 1998) ou le facteur Spl (Wang et al., 1998). Une interaction directe entre AhR et ER a été rapportée, qui conduit à la destruction des deux protéines dans le protéasome (Wormke et al., 2003).

Par ces interférences multipless la TCDD inhibe la transcription des gènes cibles de l'œstradiol tels que ER $\beta$ (Kietz et al., 2004), le récepteur de la prolactine (Lu et al., 1996), le récepteur de la progestérone (Harper et al., 1994), la 
cathepsine D (Krishnan et al., 1995) et l'activateur tissulaire du plasminogène (Gierthy et al., 1987).

Des expériences sur des primates ont suggéré que les perturbateurs endocriniens jouent un rôle dans l'endométriose, une maladie gynécologique d'étiologie inconnue dont la fréquence est en augmentation (Rier et al., 1993). Un mécanisme a été proposé impliquant la levée par la TCDD des effets inhibiteurs de la progestérone sur l'expression des métalloprotéases matricielles (Bruner-Tran et al., 1999). Dans l'espèce humaine, une seule étude épidémiologique suggère un impact de la pollution par les ligands AhR sur la fréquence de l'endométriose (Koninckx et al., 1994).

La dioxine exerce des effets pléiotropiques sur la vitamine $A$, tant au niveau de son métabolisme qu'au niveau de l'expression de gènes rétinoïdesdépendants (revue dans Nilsson et Hakansson, 2002). Les souris invalidées pour AhR présentent une altération du métabolisme hépatique de la vitamine $A$ ( $A n-$ dreola et al., 1997). Il a été récemment montré que le AhR activé par la TCDD séquestre le corépresseur SMRT ce qui permet l'activation de RAR $\alpha$ en l'absence de ligand (Widerak et al., 2005). À l'inverse, certains rétinoïdes modulent des gènes sensibles à la TCDD (Gambone et al., 2002).

\subsection{Variations inter-espèces - Données génétiques et populations à risque}

L'adéquation des modèles animaux à l'homme s'avère souvent discutable. L'existence d'importantes variations inter-espèces sur le plan de la réactivité des récepteurs hormonaux aux perturbateurs endocriniens doit être prise en compte dans l'interprétation des résultats (Honkakoski et al., 2004 ; Thomas, 2000). Les PCB lient la protéine de transport des hormones thyroïdiennes des rongeurs mais pas la «Thyroid Binding Globulin » humaine (Lans et al., 1994). Les rats et les souris sont sensibles aux dioxines sur le plan de la cancérogenèse hépatique tandis que ces tumeurs n'apparaissent pas chez le hamster, les bovins et les humains. Cette différence est corrélée avec l'expression de la 7-hydroxycholestérol déshydrogénase qui transforme le 7-hydroxycholestérol en 7-oxocholestérol lequel est antagoniste du AhR (Savouret et al., 2001).

De nombreux auteurs ont évoqué une influence génétique sur les effets des xénobiotiques, notamment par le polymorphisme des enzymes de la détoxification, qu'il s'agisse des cytochromes P-450 de phase I ou des enzymes de conjugaison de phase II (glutathion-S-transférases; N-acétyl transférase; UDPglucuronyltransférases ou sulfotransférases (pour revue : Daly, 2003). L'absence de la glutathion-S-transférase M1 ainsi que le génotype acétyleur lent de la NAT2 sont associés à une sensibilité accrue aux effets du tabac (Norppa, 2004). 
Les personnes qui manipulent professionnellement ces substances à effet perturbateur sont particulièrement exposées. Toutefois, une revue récente reprenant les données épidémiologiques disponibles sur les travailleurs de l'industrie les juge insuffisantes en termes de taille des populations étudiées et de variété de paramètres (Pilliere, 2002).

À côté des populations à risque, il existe des périodes à risque : la vieillesse, la grossesse et la période fotale. Les données humaines sont très rares. Certains auteurs s'attachent à définir des modèles toxicocinétiques spécifiques des âges "fragiles» de la vie (Clewell et al., 2002). Il faut signaler le faible nombre d'études portant sur la population historiquement la plus exposée, à savoir la population de la péninsule indochinoise à l'époque de la deuxième guerre du Viêtnam. Rappelons que le défoliant « agent orange » (ou 2, 4, 5, T), utilisé pour révéler le tracé des routes militaires dans la jungle, était contaminé par la TCDD. Une seule étude portant sur trente femmes rapporte que les deux tiers ont eu des enfants handicapés ou ont subi des fausses couches (Le et Johansson, 2001).

\subsection{Morphologie cellulaire}

Les xénobiotiques perturbent aussi la morphologie cellulaire, notamment au niveau des jonctions communicantes. Ce sont des structures organisées de la membrane cellulaire constituées de protéines dites "connexines 》. Elles permettent le passage de petites molécules d'une cellule à l'autre et maintiennent l'assemblage des cellules entre elles. L'idée émerge actuellement selon laquelle une dislocation de ces jonctions pourrait être associée au processus de cancérogenèse (Yamasaki et al. 1999). Les xéno-œstrogènes, suspectés de jouer un rôle dans la survenue des cancers testiculaires, sont effectivement délétères sur la structure et les protéines des jonctions communicantes des cellules de Leydig (Fiorini et al., 2004 ; Mograbi et al., 2003). Les ligands AhR altèrent la structure des jonctions communicantes in vivo et in vitro dans divers types cellulaires $d^{\prime}$ une façon comparable aux xéno-œstrogènes et pourraient ainsi induire ou favoriser des cancers. C'est le cas des dioxines (Legare et al., 2000) et des PCB (Bager et al., 1997).

Les ligands AhR sont de puissants inducteurs de la chloracné. Cette éruption acnéiforme s'observe à la suite d'une altération des processus de différenciation des cellules basales des glandes sébacées et des kératinocytes (Berkers et al., 1995). Dans tous les accidents industriels où ces composés ont été impliqués, la chloracné fut considérée comme le symptôme spécifique majeur de l'intoxication et fut observée chez la majorité des personnes exposées (Suskind, 1985). Récemment la chloracné fut la manifestation spectaculaire de l'empoisonnement criminel par la dioxine d'un candidat à la présidence de l'Ukraine. 


\subsection{Maturation des cellules germinales}

Les données disponibles pour les PCB sont essentiellement animales et descriptives et l'extrapolation à l'espèce humaine est difficile. Ils pourraient agir par altération des mécanismes de polyadénylation de certains ARN messagers maternels (connexines) stockés dans le cytoplasme (Brevini-Gandolfi et al., 1999) et/ou par perturbation de la redistribution des granules corticaux (Pocar et al., 2003).

Des expériences in vivo ont démontré un effet toxique direct du benzo(a)pyrène et d'autres ligands AhR sur les oocytes (Miller et al., 1992). Plus récemment, le groupe de Tilly a montré que l'activation de AhR par les HAP dans les oocytes de souris conduit à la transactivation du gène Bax et provoque l'apoptose des oocyłes. Ce mécanisme pourrait être à l'origine de la ménopause précoce des femmes tabagiques. La TCDD ne reproduit pas ces effets car elle est incapable d'induire la transactivation du gène Bax par les DRE atypiques différant de l'élément canonique (Matikainen et al., 2001). Ces résultats sont à rapprocher des observations faites sur des oocytes issus de femmes tabagiques (oocytes surnuméraires après fertilisation in vitro) qui montrent davantage de caryotypes anormaux (Zenzes et al., 1997).

Un grand nombre d'études animales abordent les effets de la TCDD sur la fertilité mais on manque de données humaines (Pocar et al., 2003). Le groupe de Bertazzi a observé une modification du sex ratio en faveur des filles dans sa cohorte de Seveso (Pesatori et al., 2003). Les ligands AhR perturbent la spermatogenèse animale (Simanainen et al., 2004 et revue dans Wissing, 1998). La TCDD diminue la sensibilité de la LH aux mécanismes de rétrocontrôle (Mably et al., 1992) et inhibe l'ovulation induite chez le rat par le sérum de jument gravide : les ovules restent bloqués dans les follicules qui ne s'ouvrent pas et un grand nombre de follicules sont manquants (Son et al., 1999).

\subsection{Effets in utero et épigenèse}

Les perturbateurs endocriniens, en particulier les $P C B$ et xéno-œstrogènes, sont logiquement susceptibles d'agir sur le développement animal et humain au cours de l'embryogenèse et de la vie fotale. Paradoxalement, les dernières revues sur le sujet restent indécises sur l'importance de ces effets (Brevini et al., 2005; Vidaeff et Sever, 2005). Les PHB ne semblent pas en cause dans les avortements à répétition (Sugiura-Ogasawara et al., 2003).

Un nouveau corpus d'études explore l'impact des PE (essentiellement DES, xéno-œstrogènes et phyto-œstrogènes) au niveau de la toxicité épigénétique. 
Ce mécanisme est basé sur une perturbation de la méthylation des histones de la chromatine qui perdure sur plusieurs générations et provoque des effets pathologiques dans la descendance non exposée d'individus ayant été exposés, même en dehors d'une grossesse (revue dans Anway et al., 2005). Un tel mécanisme impliquant la chaperone HSP90 du récepteur ER est proposé pour le DES (Ruden et al., 2005).

\section{6 | La controverse sur la perturbation endocrine}

À la suite du travail initial de Carlsen et al. (Carlsen et al., 1992) sur l'altération de la spermatogenèse, un grand nombre d'auteurs ont rapporté des discordances dans les analyses et leurs résultats (revue dans Saidi et al., 1999). S. Safe (Safe, 1995) incrimine la méthodologie des études épidémiologiques et rapporte que si les statistiques démographiques montrent des variations de la fréquence d'hypospadias et de cryptorchidie avant 1985, le taux de ces affections n'a pas changé depuis lors et la cryptorchidie a même diminué. Dans cette même période, la fréquence du cancer du testicule a augmenté dans la plupart des pays sans qu'un lien avec la pollution industrielle soit démontré. Si l'on considère deux pays scandinaves voisins, la fréquence basse observée en Finlande et la fréquence haute observée au Danemark ne sont pas explicitées. Les analyses de la contamination par les pesticides organohalogénés ne montrent pas de différence entre malades atteints de cancer du sein et cas contrôles. En raison de leur activité généralement inférieure d'un facteur 1000 ou plus à celle de l'œstradiol, les xéno-œstrogènes industriels représentent $0,0000025 \%$ de la consommation quotidienne de phyto-œstrogènes alimentaires. Plus récemment, Safe (Safe et al., 2002) a conclu que : "... les données actuelles ne soutiennent pas l'hypothèse d'un rôle significatif des xéno-œstrogènes industriels ou agricoles... la diminution de la fertilité masculine est un fait acquis mais mineur et de peu de poids vis-à-vis des progrès généraux en santé publique... les produits pharmaceutiques contenant des œstrogènes et des progestagènes n'ont pas d'impact significatif sur la fertilité de la descendance. . . ».

Safe, Foster et Witorsch (Foster, 2003; Witorsch, 2002) ne nient pas l'existence de la perturbation hormonale mais ils considèrent qu'elle a été exagérée par des méthodologies imparfaites. Ils mettent en doute l'implication des xénoœstrogènes industriels.

La directive européenne relative aux eaux destinées à la consommation humaine (article 15, 3-11-1998) considère qu'« il n'existe pas de preuves suffisantes permettant d'établir... des valeurs paramétriques en ce qui concerne les produits chimiques responsables de dérèglements endocriniens, mais que l'inquiétude croît quand aux effets potentiels... sur la santé humaine ». Si les 
études COMPREHEND et LOES ont montré qu'une partie conséquente des effluents en Europe ont de réels effets œstrogéniques sur les poissons, le rapport LOES indique que rien ne permet $d^{\prime}$ affirmer que les polluants à effet $P E$ sont prépondérants parmi d'autres facteurs environnementaux possibles. Le $6^{e}$ PCRD s'efforce de faire la lumière sur ces incertitudes.

La corrélation entre dioxines et cancer du sein dans la population de Seveso

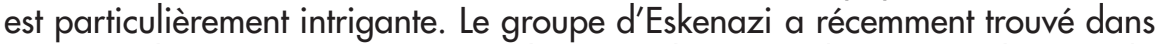
cette population une augmentation du risque de cancer du sein corrélée avec la concentration sérique de TCDD (Warner et al., 2002). Ces résultats contrastent avec ceux de Bertazzi qui n'a jamais détecté cette tendance depuis le début des analyses (Bertazzi et al., 1989). Un revue récente décrit quelques cohortes montrant un lien entre dioxines et cancer du sein mais les résultats sont jugés peu significatifs (Kogevinas, 2001).

\section{7 | La détection des perturbateurs endocriniens}

\subsection{Les méthodes de détection}

La traduction, en terme de risque sanitaire, des études et des tests biomoléculaires in vitro et in vivo reste problématique. Le passage des données mécanistiques à l'effet physiopathologique est aussi d'une grande difficulté. II y a aujourd'hui un accord général sur le fait que les données in vitro n'ont pas $d^{\prime}$ autre valeur que de criblage et qu'elles ne peuvent servir à l'estimation du risque. Les connaissances apportées par les études toxicologiques « classiques 》 chez l'animal restent le corpus essentiel sur lequel se fondent les évaluations de risques de la perturbation hormonale pour l'homme.

Il faut aussi améliorer les méthodes de mesure et d'en développer de nouvelles, simples à mettre en œuvre, transportables sur le terrain et économiques. La mesure des dioxines par chromatographie gazeuse couplée à la spectrographie de masse revenant à environ 1000 euros par dosage, des campagnes de grande envergure sont peu envisageables et le développement de tests biologiques économiques est une nécessité.

On trouve, à côté des tests in vivo classiques des fonctions hormonales, des tests de détection des xéno-œstrogènes basés sur des hépatocytes de poisson (Bennetau-Pelissero et al., 2004), sur des levures (test YES) (Fidler et al., 2000) ainsi que des tests de détection des ligands AhR basés sur des lignées stables de cellules de souris exprimant un gène rapporteur sous contrôle d'un site DRE (Murk et al., 1996). L’EPA a lancé en 2002 une triple campagne de tests : 
1) in vitro par liaison des composés aux récepteurs ER et $A R$ et modulation de gènes rapporteurs, 2) ex vivo par stérö̈dogenèse sur explants de tissus et 3 ) in vivo par des tests utérotrophiques (injections sous-cutanées de rats ovariectomisés ou prépubères), test de modulation de la puberté chez le rat, test de pseudo-déclenchement de l'activité gonadique chez le poisson et test de métamorphose des amphibiens (pour les effets thyroïdiens). Cet ensemble sera complété par des tests transgénérationnels (Gray Jr. et al., 2002).

Les récepteurs orphelins (PXR, SXR, CAR $\beta, B X R$ ) pourraient présenter un intérêt dans la détection des xénobiotiques. Lee et al. (Lee et al., 2003) ont utilisé le système SXR sous la forme d'un gène rapporteur LacZ couplé au promoteur du gène du cytochrome CYP3A4 sensible à SXR pour observer une modulation par la rifampicine et le bisphénol $A$.

L'approche par les animaux-vigie semble prometteuse. Elle consiste à réaliser des amphibiens transgéniques exprimant un gène rapporteur codant pour une protéine fluorescente de méduse sous le contrôle d'un promoteur minimal et d'éléments de réponse à différentes hormones permettant de varier la cible du test (de Luze et al., 1993). En remplaçant le promoteur minimal par un promoteur tissu-spécifique il est possible d'obtenir des informations sur la tissuspécificité des effets. Ces animaux placés dans une eau à tester permettraient d'estimer directement la quantité de PE présents. Ceci est à rapprocher du « biomonitoring " qui propose l'utilisation de végétaux pour détecter les contaminations environnementales.

\subsection{L'interprétation des données}

Les critères d'interprétation classiques sont le NOAEL (no observed adverse effect level) : dose pour laquelle on n'observe pas d'effet toxique et le NHEL (no hormonal effect level) : dose pour laquelle on n'observe pas d'effet hormonal (Bolt et al., 2001). Au niveau européen, les programmes d'analyse de la perturbation endocrine par les pesticides et les plastifiants ont conduit à l'élaboration d'un concept nouveau : la marge de sécurité basée sur l'hygiène (HBMOS : hygiene-based marging of security), une évolution de la marge de sécurité (MOS). Le HBMOS intègre $d^{\prime}$ 'une part l'exposition et $d$ 'autre part la puissance de l'action des divers xénobiotiques et se calcule comme le quotient de la prise quotidienne de composé par l'activité relative de ces composés déterminée chez le rongeur. Les plastifiants xéno-œstrogènes sont présents dans l'alimentation à une dose moyenne de $1 \mu \mathrm{g} / \mathrm{kg}$ par jour. Au vu des données européennes disponibles, la prise quotidienne de p-nonylphénol est estimée à un maximum de $2 \mu \mathrm{g} / \mathrm{kg}$, celle de bisphénol A de $1 \mu \mathrm{g} / \mathrm{kg}$ et celle de l'octylphénol apparaît négligeable. Avec un facteur d'activité œstrogénique estimé à 1 pour le bisphénol 
A et à 40000 pour le $17 \alpha$-éthinyl-œstradiol, le HBMOS du bisphénol A est autour de 1000 et celui du p-nonylphénol entre 250 et 500 .

L'utilité des outils statistiques actuels est reconnue, mais leur valeur est discutable pour les molécules persistantes, auquel cas la comparaison des taux plasmatiques des composés est un meilleur témoin de l'exposition. Il y a aujourd'hui un consensus pour reconnaître que ce sont justement ces molécules à effet cumulatif qui posent les problèmes les plus sérieux. La demi-vie dans la graisse corporelle humaine peut aller jusqu'à 8-12 ans pour la TCDD, 6 ans pour le DDT. Pour les composés œstrogéniques, la demi-vie plasmatique est de 4-8 heures pour l'œstradiol et les phyto-œstrogènes et trois jours pour le DES (revue dans Degen et al., 2002). De plus, si les effets hormonaux procèdent par quanta limités, voire par pics transitoires, les xénobiotiques sont souvent résistants à la métabolisation et/ou la dégradation, ce qui les rend persistants. Cette activité constante pourrait devenir significative en dépit de sa faiblesse, autant par sa grande durée, que par sa capacité à perturber des mécanismes cycliques telles que le cycle cellulaire ou le cycle menstruel.

\section{Quelques voies de recherche}

Il faut tenir compte de l'actuel élargissement du concept de perturbation. D'une part, les xénobiotiques alimentaires (phyto-œstrogènes, additifs) rejoignent les polluants industriels dans la liste des molécules à surveiller, $d^{\prime}$ autre part la perturbation hormonale doit englober toute l'endocrinologie et non plus seulement la reproduction comme en témoignent les deux exemples du tabagisme et du diabète.

\subsection{Le tabagisme : un modèle de perturbation hormonale générale}

Les revues récentes sur la perturbation hormonale mentionnent systématiquement le tabagisme (Bonde et Storgaard, 2002; Sharara et al., 1998). La fumée de cigarette contient en effet des dioxines dont la TCDD et des HAP dont le benzo(a)pyrène (Bilimoria et Ecobichon, 1980; Muto et Takizawa, 1989) et la charge due à l'ensemble des ligands AhR peut aller jusqu'à $0,05 \mathrm{mg} / \mathrm{kg}$. Ces composés induisent CYP1A1 dans la plupart des organes (Bartsch et al., 1992; Gurtoo et al., 1983; Mattison et Thorgeirsson, 1978; Stegeman et al., 1995). CYP IA1 catalyse la mono-oxydation des hydrocarbures procarcinogènes. Leurs produits d'oxydation (comme le benzo(a)pyrène-diol-époxyde) sont 
responsables de la formation d'adduits covalents. Cette mono-oxydation est ellemême toxique : une fraction de l'oxygène activé est relarguée sous forme de superoxyde ou d'eau oxygénée, capables de dommage oxydatif sur l'ADN (Park et al., 1996). Ces deux mécanismes peuvent provoquer des cancers lorsque les mutations se situent dans les gènes de suppresseurs de tumeurs comme p53.

Dans les cellules endothéliales, la stimulation de la production de radicaux oxygénés provoque des lésions membranaires et la peroxydation des lipides qui favorisent la formation d'athérome (Toborek et al., 1995). Il a été proposé que les ligands AhR pourraient aussi être athérogènes en perturbant le métabolisme de l'acide arachidonique (Rifkind et al., 1990), puisque l'acide arachidonique et les eicosanoïdes sont des substrats de CYP1A1. Ces données concourrent à la mise en cause du tabagisme dans l'occurrence de l'ischémie cardiaque (revue dans Boyle, 1997).

Les ligands AhR augmentent l'expression de divers enzymes et cytokines proinflammatoires (interleukine $1 \beta$, prostaglandine $\mathrm{H} 2$ synthase, cyclooxygénase 2 et TNF- $\alpha$ (revue dans Vrzal et al., 2004). Le tabagisme est un facteur de risque de l'ostéoporose dans les deux sexes et il existe une corrélation entre tabagisme et diminution de la densité osseuse ou risque de fracture (Grisso et al., 1997; Johansson et Mellstrom, 1996). La relation entre tabagisme et ostéoporose n'est pas pleinement explicitée : les ligands AhR du tabac pourraient exercer un triple effet négatif sur l'os : 1) anti-œstrogénique direct;2) perturbateur direct sur le tissu osseux qui contient du AhR (Abbott et al., 1995) ; 3) perturbateur des fonctions ovariennes dont la stérö̈dogenèse. Les femmes qui fument font une ménopause plus précoce (Mattison et Thorgeirsson, 1978).

\subsection{Ligands AhR et diabète}

Certains aspects du diabète, comme la néphropathie diabétique, sont favorisés par le tabagisme (revue dans Eliasson, 2003). Les PCB augmentent le stress oxydatif et la peroxydation des lipides dans les cellules endothéliales en culture, phénomène qui pourrait être le mécanisme des lésions cellulaires et du rôle athérogène de ces molécules. Ces composés agissent sur la vasculature et provoquent des perturbations métaboliques conduisant à l'insulinorésistance. La TCDD inhibe la différenciation adipocytaire (Alexander et al., 1998) et le transport du glucose dans le tissu adipeux (Enan et Matsumura, 1994).

Sur le plan épidémiologique, Bertazzi et al., rapportent dès 1998 un " excès " de cas de diabète dans la population féminine de Seveso. Ce lien entre dioxine et diabète a été confirmé par leurs études ultérieures et par des études sur des anciens combattants du Viêtnam et des travailleurs exposés (Bertazzi et al., 1998 ; Bertazzi et al., 2001 ; Henriksen et al., 1997 ; Vena et al., 1998). 
Une corrélation a été rapportée entre le diabète et un polymorphisme du CYPIAl (Wang et al., 2002). Les résultats des prochaines enquêtes épidémiologiques détermineront si ces données correspondent à un pic passager ou à une tendance à long terme, comme pour l'association diabète/tabagisme (Muhlhauser, 1994).

\subsection{Les possibilités thérapeutiques}

Le développement de moyens thérapeutiques de protection contre les PE devrait trouver sa place à côté des techniques de détection et de prévention. Les recherches sur les anti-oxydants se sont avérées décevantes. L' $\alpha$-tocophérol (vitamine E) lie et active PXR, qui est responsable de l'induction de certains cytochromes par la rifampicine et $d^{\prime}$ autres antibiotiques. Cela pourrait stimuler la détoxification des xénobiotiques empruntant la même voie (Traber, 2004).

Le resvératrol a été récemment démontré comme un antagoniste compétitif du AhR (Casper et al., 1999). II inhibe les effets de la TCDD sur l'induction des gènes cibles (CYP $1 \mathrm{~A} 1$, promoteur du virus HIV- 1 , interleukine $1 \beta$ ). Le resvératrol exerce un effet protecteur in vivo contre l'activation du AhR par le benzo(a)pyrène sur l'os et les cellules germinales (Revel et al., 2003; Singh et al., 2000). L'impact des molécules polycycliques et/ou halogénées (pollution et tabac) dans la perturbation hormonale ayant lieu par le biais majoritaire du $A h R$, le resvératrol pourrait permettre de prévenir ces effets.

\section{Recommandations}

Au niveau institutionnel, les premières constatations $d^{\prime}$ instances comme le CEFIC montrent la place négligeable de la France dans les structures internationales, en particulier européennes, décrites au paragraphe 2 « Initiatives internationales 》 (5 projets sur 185). II importe de remédier à cet état de fait en adaptant les organismes français au fonctionnement européen.

Au niveau scientifique et épidémiologique il serait souhaitable de :

- tenir compte de l'actuel élargissement du concept de perturbation hormonale qui est en constante évolution. D'une part, les xénobiotiques alimentaires (phyto-œstrogènes, additifs) rejoignent les polluants industriels dans la liste des molécules à surveiller, d'autre part la perturbation hormonale doit englober toute l'endocrinologie et non plus seulement la reproduction, comme en témoignent les deux exemples du tabagisme et du diabète ; 
- soutenir la recherche épidémiologique (particulièrement sur les populations féminines). Évaluer spécifiquement la vulnérabilité ou l'exposition particulière de certaines fractions de la population. Une insuffisance de distinction entre population globale et population à risque pourrait être un facteur d'erreur dans l'appréciation de la perturbation hormonale. II semble approprié de faire rentrer l'étude de la perturbation hormonale dans l'analyse des risques professionnels. En cas d'anomalie, celle-ci pourrait être recherchée dans la population générale. II faut tenir compte du fait que les effets allégués sur le risque de cancers peuvent être le résultat d'expositions passées à des produits qui ne sont plus utilisés. Les effets à court délai de latence comme l'atteinte de la fertilité peuvent aussi bien résulter de produits anciens persistants que de ceux d'utilisation actuelle;

- revoir et développer les méthodes $d$ 'analyse, chimiques ou biologiques. Ce n'est pas la toxicité des contaminants environnementaux qui est sujette à débat, mais la réalité de sa traduction sous la forme d'une perturbation hormonale chez l'animal et l'homme. Cela requiert un renforcement de la recherche fondamentale visant à élucider les mécanismes d'action des xénobiotiques et développer la production de marqueurs, de techniques de détection et de mesure ainsi que d'agents thérapeutiques;

- documenter les expositions du public aux perturbateurs endocriniens, ce qui suppose un effort important de caractérisation de la contamination des milieux (air, eau, aliments) susceptibles d'être des vecteurs d'exposition. Il faudrait établir les mesures à prendre pour minimiser l'impact des phyto-œstrogènes alimentaires (soja) si les évaluations épidémiologiques le justifient. Une norme d'apports alimentaires recommandés pourrait être établie ;

- discuter des modalités d'application du principe de précaution pour les nouvelles molécules. Les études de toxicité préalables à une autorisation de mise sur le marché de nouvelles molécules pourraient comporter des tests spécifiques d'activité endocrinienne. En cas de positivité, une étude bénéfice/risque devrait être obligatoire. Alternativement, on pourrait admettre la création d'une nouvelle catégorie de "perturbateurs hormonaux » à côté des trois classiques (cancérigènes, mutagènes, reprotoxiques) et que tout nouveau produit montrant ce type d'activité doive par principe se voir refuser son autorisation de mise sur le marché, comme c'est le cas au niveau de l'Union européenne pour les produits mutagènes.

\section{Remerciements}

Les auteurs remercient les personnes qui suivent pour leur aide et/ou leurs documents. 
Dr Robert Barouki, Inserm, Paris

Mr Jacques Desarnauts, ex-Président de l'Action Chimie-Écologie du groupe Ecrin.

Dr André Guillozou, Inserm, Rennes

Dr Marie-Laure Janex-Habibi, Suez Environnement - Cirsee, Le Pecq

Dr Bernard Jegou, Inserm, Rennes

Mme Myriam Leveugle, groupe Ecrin

Pr Edwin Milgrom, Hôpital et Faculté de médecine du Kremlin-Bicêtre, U. Paris XI Dr Jean-François Régnier, Atofina.

\section{Références bibliographiques}

Abbott BD. et al. (1995). Developmental expression of two members of a new class of transcription factors: I. Expression of aryl hydrocarbon receptor in the C57BL/6N mouse embryo. Dev Dyn, 204 : 133-143.

Alexander DL. et al. (1998). Aryl-hydrocarbon receptor is an inhibitory regulator of lipid synthesis and of commitment to adipogenesis. J Cell Sci, 111 : $3311-3322$.

Andreola F. et al. (1997). Aryl hydrocarbon receptor knockout mice (AHR-/-) exhibit liver retinoid accumulation and reduced retinoic acid metabolism. Cancer Res, 57 : 2835-2838.

Anway MD. et al. (2005). Epigenetic transgenerational actions of endocrine disruptors and male fertility. Science, 308 : 1466-1469.

Aranda A. et Pascual A. (2001). Nuclear hormone receptors and gene expression. Physiol Rev, 81 : 1269-1304.

Arlt VM. et al. (2004). DNA adducts and mutagenic specificity of the ubiquitous environmental pollutant 3-nitrobenzanthrone in Muta Mouse. Environ Mol Mutagen, 43 : 186-195.

Ayotte P. et al. (1997). PCBs and dioxin-like compounds in plasma of adult Inuit living in Nunavik (Arctic Quebec). Chemosphere, 34 : 1459-1468.

Baccarelli A. et al. (2000). Occupational and environmental agents as endocrine disruptors: experimental and human evidence. J Endocrinol Invest, 23 : 771-781.

Bachour G. et al. (1998). Species and organ dependence of PCB contamination in fish, foxes, roe deer, and humans. Arch Environ Contam Toxicol, 35 : 666-673. 
Bager Y. et al. (1997). The ability to alter the gap junction protein expression outside GST-P positive foci in liver of rats was associated to the tumour promotion potency of different polychlorinated biphenyls. Chem Biol Interact, 103 : 199-212.

Barlow NJ. et al. (2003). Quantitative changes in gene expression in fetal rat testes following exposure to di(n-butyl) phthalate. Toxicol Sci, 7 : 431-441.

Bartsch H. et al. (1992). Carcinogen metabolism in human lung tissues and the effect of tobacco smoking: results from a case-control multicenter study on lung cancer patients. Environ Health Perspect, 98 : 119-124.

Benassayag C. et al. (2002). Phytoestrogens as modulators of steroid action in target cells. J Chromatogr B Analyt Technol Biomed Life Sci, 777 : 233-248.

Bendz D. et al. (2005). Occurrence and fate of pharmaceutically active compounds in the environment, a case study: Hoje River in Sweden. J Hazard Mater, 122 : 195-204.

Bennetau-Pelissero C. et al. (2004). Screening for oestrogenic activity of plant and food extracts using in vitro trout hepatocyte cultures. Phytochem Anal, $15: 40-45$.

Berkers JA. et al. (1995). Interactive effects of 2,3,7,8-tetrachlorodibenzo-pdioxin and retinoids on proliferation and differentiation in cultured human keratinocytes: quantification of cross-linked envelope formation. Arch Toxicol, 69 : 368-378.

Bertazzi PA. et al. (1998). The Seveso studies on early and long-term effects of dioxin exposure: a review. Environ Health Perspect, 106 Suppl 2 : 625-633.

Bertazzi PA. et al. (2001). Health effects of dioxin exposure: a 20-year mortality study. Am J Epidemiol, 153 : 1031-1044.

Bertazzi PA. et al. (1989). Ten-year mortality study of the population involved in the Seveso incident in 1976. Am J Epidemiol, $129: 1187-1200$.

Bilimoria MH. et Ecobichon DJ. (1980). Responses of rodent hepatic, renal and pulmonary aryl hydrocarbon hydroxylase following exposure to cigarette smoke. Toxicology, 15 : 83-89.

Bolt HM. et al. (2001). Comparative assessment of endocrine modulators with oestrogenic activity: I. Definition of a hygiene-based margin of safety (HBMOS) for xeno-oestrogens against the background of European developments. Arch Toxicol, 74 : 649-662.

Bonde JP. et Storgaard L. (2002). How work-place conditions, environmental toxicants and lifestyle affect male reproductive function. Int J Androl, 25 : 262-268. 
Boyle P. (1997). Cancer, cigarette smoking and premature death in Europe: a review including the Recommendations of European Cancer Experts Consensus Meeting, Helsinki, October 1996. Lung Cancer, 17 : 1-60.

Brevini TA. et al. (2005). Effects of endocrine disruptors on developmental and reproductive functions. Curr Drug Targets Immune Endocr Metabol Disord, $5: 1-10$.

Brevini-Gandolfi TA. et al. (1999). Changes in poly(A) tail length of maternal transcripts during in vitro maturation of bovine oocytes and their relation with developmental competence. Mol Reprod Dev, 52 : 427-433.

Brown NA. et al. (2000). A review of the developmental and reproductive toxicity of styrene. Regul Toxicol Pharmacol, 32 : 228-247.

Bruchet A. et Janex-Habibi ML. (2004). Endocrine disruptors in environmental and drinking waters: a review. Techniques Sciences Methodes, 4 : 81-90.

Bruner-Tran KL. et al. (1999). The Potential Role of Environmental Toxins in the Pathophysiology of Endometriosis. Gynecol Obstet Invest, 48 Suppl S1 : 4556.

Carlsen E. et al. (1992). Evidence for decreasing quality of semen during past 50 years. Bmi, $305: 609-613$.

Carlson DB. et Perdew GH. (2002). A dynamic role for the Ah receptor in cell signaling? Insights from a diverse group of Ah receptor interacting proteins. J Biochem Mol Toxicol, 16 : 317-325.

Casper RF. et al. (1999). Resveratrol has antagonist activity on the aryl hydrocarbon receptor: implications for prevention of dioxin toxicity. Mol Pharmacol, 56 : 784-790.

Choe S-Y. et al. (2003). Evaluation of estrogenicity of major heavy metals. Science Total Environment, 312: 15-21.

Clark LC. et Portier KM. (1979). Diethylstilbestrol and the risk of cancer. N Engl J Med, 300 : 263-264.

Clewell HJ. et al. (2002). Review and evaluation of the potential impact of ageand gender-specific pharmacokinetic differences on tissue dosimetry. Crit Rev Toxicol, 32 : 329-389.

Collins S. et Marletta MA. (1984). Carcinogen-binding proteins. High-affinity binding sites for benzo[a]pyrene in mouse liver distinct from the Ah receptor. Mol Pharmacol, 26 : 353-359. 
Cooke GM. et al. (1998). Effects of in utero and lactational exposure to 2,3,7,8tetrachlorodibenzo-p-dioxin (TCDD) on serum androgens and steroidogenic enzyme activities in the male rat reproductive tract. J Steroid Biochem Mol Biol, 67 : 347-354.

Corton JC. et Lapinskas PJ. (2005). Peroxisome proliferator-activated receptors: mediators of phthalate ester-induced effects in the male reproductive tract? Toxicol Sci, 83 : 4-17.

Curtis LR. (2001). Organophosphate antagonism of the androgen receptor. Toxicol Sci, $60: 1-2$.

Daly AK. (2003). Pharmacogenetics of the major polymorphic metabolizing enzymes. Fundam Clin Pharmacol, $17: 27-41$.

de Lemos ML. (2001). Effects of soy phytoestrogens genistein and daidzein on breast cancer growth. Ann Pharmacother, 35 : 1118-1121.

de Luze A. et al. (1993). Thyroid hormone-dependent transcriptional regulation of exogenous genes transferred into Xenopus tadpole muscle in vivo. Proc Natl Acad Sci USA, 90 : 7322-7326.

Degen GH. et al. (2002). Integration of mechanistic data in the toxicological evaluation of endocrine modulators. Toxicol Lett, 127 : 225-237.

Denison MS. et Nagy SR. (2003). Activation of the aryl hydrocarbon receptor by structurally diverse exogenous and endogenous chemicals. Annu Rev Pharmacol Toxicol, 43 : 309-334.

Derfoul A. et al. (2003). Estrogenic endocrine disruptive components interfere with calcium handling and differentiation of human trophoblast cells. J Cell Biochem, 89 : 755-770.

DiBartolomeis MJ. et al. (1987). Altered regulation of adrenal steroidogenesis in 2,3,7,8-tetrachlorodibenzo-p-dioxin-treated rats. Biochem Pharmacol, 36 : $59-67$.

Dixon RA. et Ferreira D. (2002). Genistein. Phytochemistry, 60 : 205-21 1.

Doering DD. et al. (2002). Effects of butyltins on human 5alpha-reductase type 1 and type 2 activity. Steroids, $67: 859-867$.

Duan R. et al. (1999). Transcriptional activation of c-fos protooncogene by 17beta-estradiol: mechanism of aryl hydrocarbon receptor-mediated inhibition. Mol Endocrinol, 13 : 1511-1521.

Eliasson B. (2003). Cigarette smoking and diabetes. Progress in Cardiovascular Diseases, 45 : 405-413. 
Enan E. et al. (1998). Use of c-Src and c-Fos knockout mice for the studies on the role of c-Src kinase signaling in the expression of toxicity of TCDD. J Biochem Mol Toxicol, 12 : 263-274.

Enan E. et al. (1992). TCDD (2,3,7,8-tetrachlorodibenzo-P-dioxin) causes reduction in glucose uptake through glucose transporters on the plasma membrane of the guinea pig adipocyte. J Environ Sci Health B, 27 : 495-510.

Enan E. et Matsumura F. (1994). Significance of TCDD-induced changes in protein phosphorylation in the adipocyte of male guinea pigs. J Biochem Toxicol, 9 : 159-170.

Erdman JW. Jr. et al. (2004). Not all soy products are created equal: caution needed in interpretation of research results. J Nutr, 134 : 1229S-1233S.

Eskenazi B. et al. (2003). Maternal serum dioxin levels and birth outcomes in women of Seveso, Italy. Environ Health Perspect, 111 : 947-953.

Fidler AE. et al. (2000). Screening the foods of an endangered parrot, the kakapo (Strigops habroptilus), for oestrogenic activity using a recombinant yeast bioassay. Reprod Fertil Dev, 12 : 191-199.

Fiorini C. et al. (2004). Sertoli cell junctional proteins as early targets for different classes of reproductive toxicants. Reproductive Toxicology, 18 : 413421.

Foster WG. (2003). Do environmental contaminants adversely affect human reproductive physiology? J Obstet Gynaecol Can, 25 : 33-44.

Gambone C.J. et al. (2002). Unique property of some synthetic retinoids: activation of the aryl hydrocarbon receptor pathway. Mol Pharmacol, 61 : 334-342.

Garcia-Morales P. et al. (1994). Effect of cadmium on estrogen receptor levels and estrogen-induced responses in human breast cancer cells. J Biol Chem, 269 : 16896-16901.

Gierthy JF. et al. (1987). Suppression of estrogen-regulated extracellular tissue plasminogen activator activity of MCF-7 cells by $2,3,7,8$-tetrachlorodibenzop-dioxin. Cancer Res, 47 : 6198-6203.

Gillesby BE. et al. (1997). Identification of a motif within the $5^{\prime}$ regulatory region of pS2 which is responsible for AP-1 binding and TCDD-mediated suppression. Biochemistry, 36 : 6080-6089.

Govedard C. et al. (2004). Dietary polyphenols increase the paraoxonase-1 gene expression by an AhR-dependent mechanism. Mol Cell Biol, 24 : 5209 5222. 
Gray LE. Jr. et al. (2000). Perinatal exposure to the phthalates DEHP, BBP, and DINP, but not DEP, DMP, or DOTP, alters sexual differentiation of the male rat. Toxicol Sci, 58 : 350-365.

Gray LE. Jr. et al. (2002). Xenoendocrine disrupters-tiered screening and testing. Filling key data gaps. Toxicology, 181-182 : 371-382.

Gray LE. et al. (2001). Effects of environmental antiandrogens on reproductive development in experimental animals. Hum Reprod Update, 7 : 248-264.

Grisso JA. et al. (1997). Risk factors for hip fracture in men. Hip Fracture Study Group. Am J Epidemiol, 145 : 786-793.

Gurtoo HL. et al. (1983). Population distribution of placental benzo(a)pyrene metabolism in smokers. Int J Cancer, 31 : 29-37.

Harper N. et al. (1994). Inhibition of estrogen-induced progesterone receptor in MCF-7 human breast cancer cells by aryl hydrocarbon (Ah) receptor agonists. Mol Cell Endocrinol, 104 : 47-55.

Heimler I. et al. (1998). Dioxin perturbs, in a dose- and time-dependent fashion, steroid secretion, and induces apoptosis of human luteinized granulosa cells. Endocrinology, 139 : 4373-4379.

Henriksen GL. et al. (1997). Serum dioxin and diabetes mellitus in veterans of Operation Ranch Hand. Epidemiology, 8 : 252-258.

Henson MC. et Chedrese PJ. (2004). Endocrine disruption by cadmium, a common environmental toxicant with paradoxical effects on reproduction. Exp Biol Med (Maywood), 229 : 383-392.

Honkakoski P. et al. (2004). Effects of triaryl phosphates on mouse and human nuclear receptors. Biochem Pharmacol, 67 : 97-106.

Hu H. (2000). Exposure to metals. Prim Care, 27 : 983-996.

Hunt PA. et al. (2003). Bisphenol A exposure causes meiotic aneuploidy in the female mouse. Curr Biol, $13: 546-553$.

Hurley PM. (1998). Mode of carcinogenic action of pesticides inducing thyroid follicular cell tumors in rodents. Environ Health Perspect, 106 : 437-445.

Inserm (2000). Dioxines dans l'environnement: Quels risques pour la santé? Inserm, Paris.

Iwasaki T. et al. (2002). Polychlorinated biphenyls suppress thyroid hormoneinduced transactivation. Biochem Biophys Res Commun, 299 : 384-388. 
Johansson C. et Mellstrom D. (1996). An earlier fracture as a risk factor for new fracture and its association with smoking and menopausal age in women. Maturitas, 24 : 97-106.

Johansson M. et al. (1998). Interactions between methylsulfonyl PCBs and the glucocorticoid receptor. Environ Health Perspect, 106 : 769-772.

Johnson MD. et al. (2003). Cadmium mimics the in vivo effects of estrogen in the uterus and mammary gland. Nat Med, 9 : 1081-1084.

Kaltreider RC. et al. (2001). Arsenic alters the function of the glucocorticoid receptor as a transcription factor. Environ Health Perspect, 109 : 245-251.

Kavlock R. et al. (2002). NTP Center for the Evaluation of Risks to Human Reproduction: phthalates expert panel report on the reproductive and developmental toxicity of di-n-octyl phthalate. Reprod Toxicol, $16: 721-734$.

Kavlock RJ. et al. (1996). Research needs for the risk assessment of health and environmental effects of endocrine disruptors: a report of the U.S. EPAsponsored workshop. Environ Health Perspect, 104 Suppl 4 : 715-740.

Kietz S. et al. (2004). The Ah receptor inhibits estrogen-induced estrogen receptor beta in breast cancer cells. Biochem Biophys Res Commun, 320 : 76-82.

Klaunig JE. et al. (2003). PPARalpha agonist-induced rodent tumors: modes of action and human relevance. Crit Rev Toxicol, 33 : 655-780.

Koch HM. et al. (2004). NTP center for the evaluation of risks to human reproduction reports on phthalates: addressing the data gaps. Reprod Toxicol, 18 : 759-760; author reply 761-754.

Kogevinas M. (2001). Human health effects of dioxins: cancer, reproductive and endocrine system effects. Hum Reprod Update, 7 : 331-339.

Koninckx PR. et al. (1994). Dioxin pollution and endometriosis in Belgium. Hum Reprod, 9 : 1001-1002.

Kreuzer PE. et al. (1997). 2,3,7,8-Tetrachlorodibenzo-p-dioxin (TCDD) and congeners in infants. A toxicokinetic model of human lifetime body burden by TCDD with special emphasis on its uptake by nutrition. Arch Toxicol, 71 : 383-400.

Krishnan V. et al. (1995). Molecular mechanism of inhibition of estrogeninduced cathepsin $D$ gene expression by 2,3,7,8-tetrachlorodibenzo-pdioxin (TCDD) in MCF-7 cells. Molecular Cellular Biology, 15 : 6710-6719.

Lackmann GM. et al. (2004). Organochlorine compounds in breast-fed vs. bottle-fed infants: preliminary results at six weeks of age. Sci Total Environ, 329 : 289-293. 
Lai ZW. et al. (1996). Identification of Dioxin-Responsive Elements (Dres) in the 5 'regions of Putative Dioxin-Inducible Genes. Chem Biol Inter, 100 : 97-112.

Lans MC. et al. (1994). Different competition of thyroxine binding to transthyretin and thyroxine-binding globulin by hydroxy-PCBs, PCDDs and PCDFs. Eur J Pharmacol, 270 : 129-136.

Latendresse JR. et al. (1995). Toxic effects of butylated triphenyl phosphatebased hydraulic fluid and tricresyl phosphate in female F344 rats. Vet Pathol, 32 : 394-402.

Le TN. et Johansson A. (2001). Impact of chemical warfare with agent orange on women's reproductive lives in Vietnam: a pilot study. Reprod Health Matters, $9: 156-164$.

Lee MR. et al. (2003). An in vitro bioassay for xenobiotics using the SXR-driven human CYP3A4/lacZ reporter gene. Int J Toxicol, 22 : 207-213.

Legare ME. et al. (2000). 2,3,7,8-Tetrachlorodibenzo-p-dioxin alters hippocampal astroglia-neuronal gap junctional communication. Neurotoxicology, 21 : 1109-1116.

Longo LD. (1980). Environmental pollution and pregnancy: risks and uncertainties for the fetus and infant. Am J Obstet Gynecol, 137 : 162-173.

Lu YF. et al. (1996). Inhibition of prolactin receptor gene expression by 2,3,7,8tetrachlorodibenzo-p-dioxin in MCF-7 human breast cancer cells. Arch Biochem Biophys, 332 : 35-40.

Lutz WK. et al. (2005). Different types of combination effects for the induction of micronuclei in mouse lymphoma cells by binary mixtures of the genotoxic agents MMS, MNU, and genistein. Toxicol Sci, 86 : 318-323.

Mably TA. et al. (1992). In utero and lactational exposure of male rats to 2,3,7,8-tetrachlorodibenzo-p-dioxin. 2. Effects on sexual behavior and the regulation of luteinizing hormone secretion in adulthood. Toxicol Appl Pharmacol, 114 : 108-117.

Maloney EK. et Waxman DJ. (1999). trans-Activation of PPARalpha and PPARgamma by structurally diverse environmental chemicals. Toxicol Appl Pharmacol, 161 : 209-218.

Masuyama H. et al. (2001). The expression of pregnane $\mathrm{X}$ receptor and its target gene, cytochrome P450 3A1, in perinatal mouse. Mol Cell Endocrinol, 172 : 47-56.

Matikainen T. et al. (2001). Aromatic hydrocarbon receptor-driven Bax gene expression is required for premature ovarian failure caused by biohazardous environmental chemicals. Nat Genet, 28 : 355-360. 
Mattingly RF. et Stafl A. (1976). Cancer risk in diethylstilbestrol-exposed offspring. Am J Obstet Gynecol, 126 : 543-548.

Mattison DR. et Thorgeirsson SS. (1978). Smoking and industrial pollution, and their effects on menopause and ovarian cancer. Lancet, 1 : 187-188.

McKee RH. et al. (2004). NTP center for the evaluation of risks to human reproduction reports on phthalates: addressing the data gaps. Reprod Toxicol, $18: 1-22$.

McKinney J. et al. (1987). Polychlorinated biphenyls and related compound interactions with specific binding sites for thyroxine in rat liver nuclear extracts. J Med Chem, 30 : 79-86.

Milgrom E. et al. (1973). Acidophilic activation of steroid hormone receptors. Biochemistry, 12 : 5198-5205.

Miller MM. et al. (1992). The effect of benzo(a)pyrene on murine ovarian and corpora lutea volumes. Am J Obstet Gynecol, 166 : 1535-1541.

Mishra SI. et al. (2003). Phytoestrogens and breast cancer prevention: what is the evidence? Am J Obstet Gynecol, 188 : S66-70.

Mograbi B. et al. (2003). Aberrant Connexin 43 endocytosis by the carcinogen lindane involves activation of the ERK/mitogen-activated protein kinase pathway. Carcinogenesis, 24 : 1415-1423.

Moore BS. (1999). Biosynthesis of marine natural products: microorganisms and macroalgae. Nat Prod Rep, 16 : 653-674.

Moore RW. et al. (1991). 2,3,7,8-Tetrachlorodibenzo-p-dioxin inhibits steroidogenesis in the rat testis by inhibiting the mobilization of cholesterol to cytochrome P450scc. Toxicol Appl Pharmacol, 109 : 85-97.

Muhlhauser I. (1994). Cigarette smoking and diabetes: an update. Diabet Med, $11: 336-343$.

Munro IC. et al. (1999). A procedure for the safety evaluation of flavouring substances. Joint FAO/WHO Expert Committee on Food Additives. Food Chem Toxicol, 37 : 207-232.

Murk AJ. et al. (1996). Chemical-activated luciferase gene expression (CALUX): a novel in vitro bioassay for Ah receptor active compounds in sediments and pore water. Fundam Appl Toxicol, 33 : 149-160.

Muto H. et Takizawa Y. (1989). Dioxins in cigarette smoke. Arch Environ Health, 44 : 171-174. 
Nagel SC. et al. (1999). Developmental effects of estrogenic chemicals are predicted by an in vitro assay incorporating modification of cell uptake by serum. J Steroid Biochem Mol Biol, 69 : 343-357.

Nau H. et Bass R. (1981). Transfer of 2,3,7,8-tetrachlorodibenzo-p-dioxin (TCDD) to the mouse embryo and fetus. Toxicology, $20: 299-308$.

Nilsson CB. et Hakansson H. (2002). The retinoid signaling system: a target in dioxin toxicity. Crit Rev Toxicol, 32 : 21 1-232.

Nordby KC. et al. (2005). Indicators of mancozeb exposure in relation to thyroid cancer and neural tube defects in farmers' families. Scand J Work Environ Health, $31:$ : 89-96.

Norppa H. (2004). Cytogenetic biomarkers and genetic polymorphisms. Toxicol Lett, $149:$ 309-334.

Pages N. et al. (2002). Reproductive toxicity of lindane. J Soc Biol, 196 : 325338.

Papadopoulos V. et al. (1997). Peripheral benzodiazepine receptor in cholesterol transport and steroidogenesis. Steroids, $62: 21-28$.

Park JY. et al. (1996). Induction of cytochrome P4501A1 by 2,3,7,8tetrachlorodibenzo-p-dioxin or indolo(3,2-b)carbazole is associated with oxidative DNA damage. Proceedings of the National Academy of Sciences of the United States of America, 93 : 2322-2327.

Perdew GH. et Hollenback CE. (1990). Analysis of photoaffinity-labeled aryl hydrocarbon receptor heterogeneity by two-dimensional gel electrophoresis. Biochemistry, 29 : 6210-6214.

Pesatori AC. et al. (2003). Short- and long-term morbidity and mortality in the population exposed to dioxin after the "Seveso accident". Ind Health, 41 : 127-138.

Peterson J. et al. (2003). Flavonoid intake and breast cancer risk: a case-control study in Greece. Br J Cancer, 89 : 1255-1259.

Piasek M. et al. (1996). Biomarkers of heavy metal reproductive effects and interaction with essential elements in experimental studies on female rats. Arh Hig Rada Toksikol, 47 : 245-259.

Pieklo R. et al. (2000). 2,3,7,8-Tetrachlorodibenzo-p-dioxin alters follicular steroidogenesis in time- and cell-specific manner. Exp Clin Endocrinol Diabetes, 108 : 299-304.

Pilliere F. (2002). In Documents pour le Médecin du Travail, Nr 92. INRS, ed., INRS, Paris, p. 337-352. 
Pocar P. et al. (2003). The impact of endocrine disruptors on oocyte competence. Reproduction, 125 : 313-325.

Pohl HR. et Hibbs BF. (1996). Breast-feeding exposure of infants to environmental contaminants: a public health risk assessment viewpoint: chlorinated dibenzodioxins and chlorinated dibenzofurans. Toxicol Ind Health, 12 : 593611 .

Polkowski K. et Mazurek AP. (2000). Biological properties of genistein. A review of in vitro and in vivo data. Acta Pol Pharm, 57 : 135-155.

Porter WP. et al. (1993). Groundwater pesticides: interactive effects of low concentrations of carbamates aldicarb and methomyl and the triazine metribuzin on thyroxine and somatotropin levels in white rats. J Toxicol Environ Health, 40 : 15-34.

Rawlings NC. et al. (1998). Effects of the pesticides carbofuran, chlorpyrifos, dimethoate, lindane, triallate, trifluralin, 2,4-D, and pentachlorophenol on the metabolic endocrine and reproductive endocrine system in ewes. J Toxicol Environ Health A, $54: 21-36$.

Revel A. et al. (2003). Resveratrol, a natural aryl hydrocarbon receptor antagonist, protects lung from DNA damage and apoptosis caused by benzo[a]pyrene. J Appl Toxicol, 23 : 255-261.

Rier SE. et al. (1993). Endometriosis in rhesus monkeys (Macaca mulatta) following chronic exposure to 2,3,7,8-tetrachlorodibenzo-p-dioxin. Fundam. Appl Toxicol, 21 : 433-441.

Rifkind AB. et al. (1990). Arachidonic acid metabolism by dioxin-induced cytochrome P-450: a new hypothesis on the role of P-450 in dioxin toxicity. Biochem Biophys Res Commun, 172 : $1180-1188$.

Rowlands JC. et Gustafsson JA. (1997). Aryl hydrocarbon receptor-mediated signal transduction. Crit Rev Toxicol, 27 : 109-134.

Ruden DM. et al. (2005). Hsp90 and environmental impacts on epigenetic states: a model for the trans-generational effects of diethylstibesterol on uterine development and cancer. Hum Mol Genet, 14 (1) : R149-155.

Safe S. et al. (1998). Ah receptor agonists as endocrine disruptors: antiestrogenic activity and mechanisms. Toxicol Lett, 102-103 : 343-347.

Safe S. et Wormke M. (2003). Inhibitory aryl hydrocarbon receptor-estrogen receptor alpha cross-talk and mechanisms of action. Chem Res Toxicol, 16 : 807-816.

Safe SH. (1995). Environmental and dietary estrogens and human health: is there a problem? Environ Health Perspect, 103 : 346-351. 
Safe SH. et al. (2002). Problems for risk assessment of endocrine-active estrogenic compounds. Environ Health Perspect, 110 Suppl 6 : 925-929.

Saidi JA. et al. (1999). Declining sperm counts in the United States? A critical review. J Urol, $161:$ 460-462.

Savouret JF. et al. (2001). 7-ketocholesterol is an endogenous modulator for the Aryl hydrocarbon Receptor. J Biol Chem, 276 : 3054-3059.

Schonfelder G. et al. (2002). Parent bisphenol A accumulation in the human maternal-fetal-placental unit. Environ Health Perspect, 110 : A703-707.

Schultz R. et al. (2003). Expression of aryl hydrocarbon receptor and aryl hydrocarbon receptor nuclear translocator messenger ribonucleic acids and proteins in rat and human testis. Endocrinology, 144 : 767-776.

Schuur AG. et al. (1998). In vitro inhibition of thyroid hormone sulfation by hydroxylated metabolites of halogenated aromatic hydrocarbons. Chem Res Toxicol, 11 : 1075-1081.

Setchell KD. et al. (1997). Exposure of infants to phyto-oestrogens from soybased infant formula. Lancet, 350 : 23-27.

Setchell KD. et al. (1998). Isoflavone content of infant formulas and the metabolic fate of these phytoestrogens in early life. Am J Clin Nutr, 68 : 1453S-1461S.

Sharara Fl. et al. (1998). Environmental toxicants and female reproduction. Fertil Steril, 70 : 613-622.

Simanainen U. et al. (2004). Adult 2,3,7,8-tetrachlorodibenzo-p-dioxin (TCDD) exposure and effects on male reproductive organs in three differentially TCDD-susceptible rat lines. Toxicol Sci, 81 : 401-407.

Singh SU. et al. (2000). Inhibition of dioxin effects on bone formation in vitro by a newly described aryl hydrocarbon receptor antagonist, resveratrol. J Endocrinol, 167 : 183-195.

Sirtori CR. et al. (2005). Phytoestrogens: end of a tale? Ann Med, 37 : 423-438.

Skakkebaek NE. et al. (2001). Testicular dysgenesis syndrome: an increasingly common developmental disorder with environmental aspects. Hum Reprod, 16 : 972-978.

Skibola CF. et Smith MT. (2000). Potential health impacts of excessive flavonoid intake. Free Radic Biol Med, 29 : 375-383.

Son DS. et al. (1999). 2,3,7,8-Tetrachlorodibenzo-p-dioxin (TCDD) blocks ovulation by a direct action on the ovary without alteration of ovarian steroidogenesis: lack of a direct effect on ovarian granulosa and thecal-interstitial cell steroidogenesis in vitro. Reprod Toxicol, $13: 521-530$. 
Sonnenschein C. et Soto AM. (1998). An updated review of environmental estrogen and androgen mimics and antagonists. J Steroid Biochem Mol Biol, $65: 143-150$.

Stegeman JJ. et al. (1995). Induction of cytochrome P4501A1 by aryl hydrocarbon receptor agonists in porcine aorta endothelial cells in culture and cytochrome P4501 A1 activity in intact cells. Mol Pharmacol, 47 : 296-306.

Sugiura-Ogasawara M. et al. (2003). PCBs, hexachlorobenzene and DDE are not associated with recurrent miscarriage. Am J Reprod Immunol, 50 : 485489.

Sumpter JP. (1998). Reproductive effects from oestrogen activity in polluted water. Arch Toxicol Suppl, 20 : 143-150.

Suskind RR. (1985). Chloracne, "the hallmark of dioxin intoxication". Scand J Work Environ Health, 11 : 165-171.

Swan SH. et al. (2005). Decrease in anogenital distance among male infants with prenatal phthalate exposure. Environ Health Perspect, 113 : 10561061 .

Thomas P. (2000). Chemical interference with genomic and nongenomic actions of steroids in fishes: role of receptor binding. Mar Environ Res, 50 : 127 134.

Toborek M. et al. (1995). Exposure to polychlorinated biphenyls causes endothelial cell dysfunction. J Biochem Toxicol, 10 : 219-226.

Traber MG. (2004). Vitamin E, nuclear receptors and xenobiotic metabolism. Arch Biochem Biophys, 423 : 6-11.

Union européenne (2000). Directive 2000/60/CE du Parlement européen et du Conseil du 23 octobre 2000 établissant un cadre pour une politique communautaire dans le domaine de l'eau. J Off Comm Europ, L 327 : 0001 0073.

Vena J. et al. (1998). Exposure to dioxin and nonneoplastic mortality in the expanded IARC international cohort study of phenoxy herbicide and chlorophenol production workers and sprayers. Environ Health Perspect, 106 (2) : 645-653.

Vidaeff AC. et Sever LE. (2005). In utero exposure to environmental estrogens and male reproductive health : a systematic review of biological and epidemiologic evidence. Reprod Toxicol, 20 : 5-20.

Vrzal R. et al. (2004). Aromatic hydrocarbon receptor status in the metabolism of xenobiotics under normal and pathophysiological conditions. Biomed Pap Med Fac Univ Palacky Olomouc Czech Repub, 148 : 3-10. 
Waller CL. et al. (1996). Ligand-based identification of environmental estrogens. Chemical Research in Toxicology, 9 : 1240-1248.

Wang F. et al. (1998). Functional and physical interactions between the estrogen receptor Spl and nuclear aryl hydrocarbon receptor complexes. Nucleic Acids Res, 26 : 3044-3052.

Wang XL. et al. (2002). Effect of CYPIA1 Mspl polymorphism on cigarette smoking related coronary artery disease and diabetes. Atherosclerosis, 162 : 391-397.

Warner M. et al. (2002). Serum dioxin concentrations and breast cancer risk in the Seveso Women's Health Study. Environ Health Perspect, 110 : 625-628.

Whitelaw ML. et al. (1994). Identification of transactivation and repression functions of the dioxin receptor and its basic helix-loop-helix/PAS partner factor Arnt: inducible versus constitutive modes of regulation. Mol Cell Biol, 14 : 8343-8355.

Widerak M. et al. (2005). The aryl hydrocarbon receptor activates the retinoic acid receptoralpha through SMRT antagonism. Biochimie, 88 : 387-397.

Wissing M. (1998). Dioxins : current knowledge about health effects. Rev Med Brux, 19 : A367-371.

Witorsch RJ. (2002). Endocrine Disruptors: Can Biological Effects and Environmental Risks Be Predicted? Regulatory Toxicology and Pharmacology, 36 : 118-130.

Wormke M. et al. (2003). The Aryl Hydrocarbon Receptor Mediates Degradation of Estrogen Receptor alpha through Activation of Proteasomes. Mol Cell Biol, 23 : 1843-1855.

Zenzes MT. et al. (1997). Effects of cigarette smoking and age on the maturation of human oocytes. Hum Reprod, 12 : 1736-1741.

Zhang S. et al. (2003). Flavonoids as aryl hydrocarbon receptor agonists/antagonists: effects of structure and cell context. Environ Health Perspect, 111 : 1877-1882.

\section{Abréviations}

$A D N$ : acide désoxyribonucléique

Afssa : Agence française de sécurité sanitaire des aliments

AhR : aryl hydrocarbon receptor

$A R$ : androgen receptor 
ARNT : aryl hydrocarbon receptor nuclear translocator

bHLH-PAS : domaine basique/Hélice/boucle (Loop) /Hélice-domaine Per/ARNT/Sim

$B X R$ : benzoate $X$ receptor

$\mathrm{CAR} \beta \mathrm{g}$ constitutive androstane receptor

CEFIC : Conseil européen de l'industrie chimique

CIRSEE : Centre international de recherche sur l'eau et l'environnement

CYP 1A1 : cytochrome P-450 1A1

CYP 450scc : enzyme de coupure de la chaîne latérale du cholestérol

DDT : dichlorodiphényltrichloroéthane

DEHP : di-2-éthylhexyl-phtalate

DES : diéthylstilbestrol

DRE : dioxin responsive element

EPA : Environmental Protection Agency

ER : estrogen receptor

$\mathrm{FSH}$ : follicle-stimulating hormone

FXR : farnesoid $X$ receptor

GR : récepteur des glucocorticoïdes

HAP : hydrocarbures aromatiques polycycliques

HRE : hormone response element

HBMOS : hygiene-based marging of security

IFCS : Intergovernmental forum on chemical safety

IOMC : Programme interorganisation pour la gestion saine des produits chimiques

IPCS : Programme international de sécurité chimique

$\mathrm{Kd}$ : constante d'affinité

LDL : low density lipoproteins

$\mathrm{LH}$ : luteinizing hormone

LXR : liver $X$ receptor

MOS : marging of security

NHEL : no hormonal effect level

$\mu \mathrm{g}$ : microgramme

$\mu \mathrm{M}:$ micromolaire

$\mathrm{nM}$ : nanomolaire

NOAEL : no observed adverse effect level

PCB : polychlorobiphényles

PCDD : polychlorodibenzodioxines

PCDF : polychlorodibenzofuranes

PCRD : Programme commun de recherche et développement

$P E$ : perturbateur endocrinien

pg : picogramme

PHB : polyhalogénobiphényles

POP : polluant organohalogéné persistant

PPAR : peroxisome proliferator activated receptor

$P R$ : progesterone receptor

PXR : pregnane $X$ receptor 
RAR : retinoic acid receptor

ROS : reactive oxygen species

$R X R$ : récepteur $X$ de l'acide 9-cis rétinoïque

RyaR : canal calcique sensible à la ryanodine

SMRT : silencing mediator of retinoic acid and thyroid hormone receptor

STREP : Specific Targeted Research Project

SXR : steroid and xenobiotic receptor

TCDD : 2,3,7,8-tétrachlorodibenzoparadioxine

$T R$ : récepteur des hormones thyroïdiennes

TSH : thyréostiumuline

XRE : xenobiotic responsive element 